\title{
A comparative study between finite difference explicit and implicit method for predicting pressure distribution in a petroleum reservoir
}

\author{
Prince Opoku Appau ${ }^{1 *}$, Ohenewaa Kakra Dankwa², Eric Thompson Brantson ${ }^{2}$ \\ $I^{I^{*}}$ Research Institute of Enhanced Oil Recovery, China University of Petroleum, Beijing 102249, P.R. CHINA \\ ${ }^{2}$ Petroleum Engineering Department, Faculty Mineral Resources Technology, University of Mines and Technology, Tarkwa, GHANA \\ "Corresponding Author: e-mail: 2017290109@student.cup.edu.cn
}

\begin{abstract}
Predicting pressure distribution in a petroleum reservoir is principal to the reservoir's evaluation and maintenance, as pressure changes with space and time. A convenient approach to effectively achieve this task is to formulate fluid flow equations based on the reservoir characteristics and solve them numerically. Numerical method provides solutions to mathematical fluid flow models developed in a reservoir simulation. This study provides numerical solutions, using both finite difference explicit and implicit method, to a mathematical model by developing MATLAB codes to ascertain the pressure distribution for a singlephase, one-dimensional, slightly compressible fluid flow in a petroleum reservoir. Series of numerical simulations were carried out during the first year of production using timestep sizes of 1,2 and 3 days, respectively. The explicit method gave poor result (negative values for pressures) for timestep of 1 day, an outcome that is not accurate to describe the problem being solved but gave acceptable pressure results for timestep of 2 and 3 days. This shows that the efficacy of the explicit method is reliant on the chosen timestep and simulation time. In contrast, the implicit method gave a quite satisfactory results for all timesteps, and including less than 1 day, confirming the robustness and unconditionally stable nature of the implicit method. A commercial simulator (CMG software) was also employed to build a one-dimensional black oil model to validate the aforesaid results of which a close match was observed between the simulator results and the numerical solutions. This study provides insights to reservoir's pressure profile during hydrocarbon recovery beforehand so that efficient pressure maintenance decisions can be made to achieve economic hydrocarbon recovery throughout the life of the reservoir.
\end{abstract}

Keywords: finite difference formulation; explicit and implicit method; petroleum reservoir; pressure distribution; numerical reservoir simulation

DOI: http://dx.doi.org/10.4314/ijest.v11i4.3

\section{Introduction}

A petroleum reservoir is a subsurface porous medium that contains hydrocarbons trapped either structurally or stratigraphically. Therefore, describing the flow of fluid through such medium is extremely complex compared to that of flow through pipes or conduits (Ahmed and McKinney, 2005). Unlike flow in pipes or conduits, there are no definite flow paths in porous media making their flow capacity as a function of pressure estimation difficult. The analysis however of flow in porous medium has advanced over the years along two directions; experimental and analytical. Series of investigations have been conducted extensively to analyze the behaviour of numerous fluids through porous medium experimentally. Comparably, many attempts have been made to formulate laws and correlations in order to make predictions of analogous systems analytically (Ahmed and Meehan, 2011). In general, analytical solutions to mathematical models can be achieved by providing various basic assumptions that takes into account the reservoir properties, geometry and conditions at the boundary. Even so, such models cannot fully describe most fluid flow problems, thereby making them invalid. Due to the complex nature of multiphase flow, nonlinearity of their governing equations and reservoir intricacies, finding analytical solutions to practical fluid flow problems is impossible. Therefore, the only means by which such models can be solved is by using numerical methods such as finite difference or finite element (Chen, 2012). 
Reservoir simulation tends to offer numerical solutions to fluid flow problems in petroleum reservoir systems on a digital computer. According to Aziz and Serrari (1979), reservoir simulation is a skill of developing a tool to forecast the performance of hydrocarbon reservoir under different operating settings by the combination of physics, mathematics, reservoir engineering and computer programming. The conventional means of forecasting the performance of a reservoir is by experimental, mathematical and analogical method before a reservoir simulation approach is introduced (Chen, 2007). Due to extreme complexity of most reservoir systems, conventional methods cannot fully describe such systems, hence providing numerical solutions with the aid of reservoir simulators is usually the only way out in finding meaningful and reliable solutions for most actual cases (Chen, 2012). Presently, reservoir simulation has become a customary tool in the area of petroleum engineering which is extensively used for resolving a variety of hydrodynamic fluid problems involved in recovery of oil and gas from the reservoirs. For instance, Xu et al. (2019) developed embedded discrete fracture model (EDFM) for compositional reservoir simulation using corner-point grids. Their model proved reliable based on the obtained results, as well as compatible with different types of numerical solution schemes in existing simulators. Shao et al. (2019) used discrete event simulation to efficiently model the transport of solute in heterogeneous media. Sun et al. (2019) also worked on numerical simulation of free surface fluid flows through porous media using the explicit MPS method. At the end of their studies, their method was suitable for modeling free surface floes interacting with porous structures. Abdullah et al. (2019) also used multi-scale method to model and simulate two phase flow in reservoir using MRST. Shen et al. (2019) employed parallel computing techniques in simulation of two-phase flow in naturally fractured reservoirs using dual porosity. Their numerical results showed that their simulator is accurate and scalable compared to the commercial software and the numerical scheme is also effective.

A hydrocarbon recovery project is a capital intensive venture with a lot of uncertainties (risks) that needs to be evaluated and minimized to ensure effective development and production of hydrocarbons (Ertekin et al., 2007). The uncertainties includes reservoir complexity and its associated fluids, recovery mechanisms and predictive methods applicability within limits that might make them unsuitable (Aphu et al., 2018). Therefore understanding these uncertainties are paramount to the decision making process in a reservoir development project, so that they can be incorporated directly in a reservoir simulation (Hossain, 2010) through generality of data input into a simulation model that can be assessed through rigorous engineering practices coupled with precise reservoir simulation. Generally, reservoir simulation is used to predict the performance of reservoirs so that intelligent decisions can be made to enhance the economic recovery of hydrocarbons from the reservoir. It also helps provide acumens into the vigorous behaviour of a recovery process or mechanism. This makes the description of fluid flow and the pressure distribution in a petroleum reservoir to be of great importance, as pressure varies with time and location (Khormali et al., 2014).

As previously stated, the only means by which complex multi-phase fluid flow models can be solved is by using numerical methods such as finite difference, finite element, and finite volume method. In view of this, Hogarth et al. (1990), did a comparative study of finite difference methods for solving one-dimensional transport equation with an initial boundary value discontinuity. Their study revealed that the implicit method have an advantage in terms of lower CPU times over the explicit methods if a desired level of accuracy is required because they are able to use larger time steps. Marcondes et al. (2009) compared three linearization schemes used in petroleum reservoir simulation; Implicit Pressure Explicit Saturation (IMPES), Fully Implicit (FI) and Adaptive Implicit Method (AIM). The outcome of their study revealed that adaptive implicit methodologies can be a good choice when unstructured grids are present. Moghaddam and Mostaghim (2013) applied finite difference method to provide solutions to delay differential equations. Khormali et al. (2014) also studied the pressure distribution in a one dimensional reservoir system by providing numerical solutions using explicit finite difference method. Similarly, this paper focuses on providing numerical solutions, but using both the explicit forward-difference method and implicit backward-difference implicit method, to a mathematical model to predict the pressure distribution in a petroleum reservoir for a single-phase, one-dimensional, slightly compressible fluid flow. The provision of numerical solutions to the fluid flow equations through reservoir simulation will aid in the establishment of effective reservoir monitoring and pressure maintenance plans in order to improve ultimate recovery from the target reservoir and other reservoir systems alike.

\section{Research Methodology}

The ubiquitous recognition of reservoir simulation in the petroleum engineering discipline today can be ascribed to the advances in computing facilities, mathematical modeling, numerical methods, solver techniques, and visualization tools. Therefore, to effectively predict pressure distribution in a petroleum reservoir, the four main reservoir simulation stages as depicted in Figure 1 cannot be overlooked. Consequently, Chen (2007) asserts that, each stage is paramount to the reservoir simulation, hence adjusting any of these stages are sometimes necessary so that accurate performance forecast can be attained. The following procedures were adopted in the prediction of the pressure distribution of the target reservoir:

- Describe the physical problem at hand by incorporating all the essential features of the physical phenomena.

- Develop a mathematical model that describes the physical problem taking into account all the underlying assumptions in the form of PDEs.

- Develop numerical model that incorporates the mathematical model in a discretize form that is solvable using an appropriate linear solve technique.

- Develop computer programming codes using MATLAB to effectively solve for the discretized equations. 
- Compare the results obtained at the end of the simulation in order to establish the finite difference scheme that best describes the physical problem.

- Build a one-dimensional black oil model in a commercial simulator (CMG software) by incorporating the input data and underlying assumptions to validate the results of the finite difference formulation that best describes the physical problem.

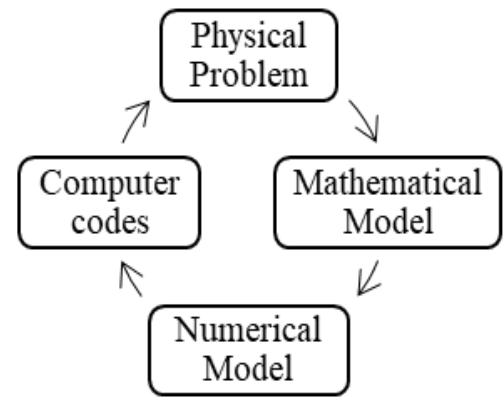

Figure 1. Reservoir simulation stages

\subsection{Physical Problem (Model) Description}

Considering a horizontal, one dimensional, slightly compressible fluid (oil) flow for the block centered grid as shown in Figure 2. The reservoir has the two external boundaries closed to flow but has an internal boundary in the form of a producing well which is located in the gridblock 4 with a production rate of $150 \mathrm{STB} / \mathrm{Day}$. The rock and fluid properties for physical problem are presented in Table 1.

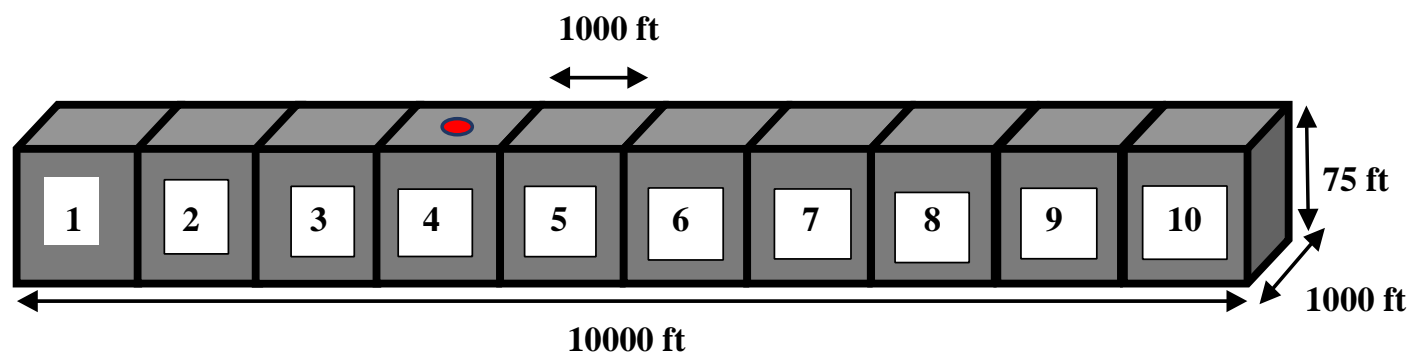

Figure 2. Reservoir Gridblocks

Table 1. Reservoir Rock and Fluid Properties

\begin{tabular}{ll}
\hline Reservoir Parameters & Numerical values \\
\hline Grid-block dimensions $(\mathrm{x}, \mathrm{y}, \mathrm{z})$ & $\Delta \mathrm{x}=\Delta \mathrm{y}=1000 \mathrm{ft} ; \Delta \mathrm{z}=75 \mathrm{ft}$ \\
Permeability (x-direction), $k_{x}$ & 0.015 Darcy \\
Oil viscosity, $\mu$ & $10 \mathrm{cP}$ \\
Oil Formation Volume Factor, B & $1.0 \mathrm{RB} / \mathrm{STB}$ \\
Porosity, $\varphi$ & 0.18 \\
Total Compressibility, $C_{t}$ & $0.0000035 \mathrm{psi}^{-1}$ \\
Initial Reservoir Pressure, $P_{i}$ & $6000 \mathrm{psia}$ \\
Production rate, $q$ & $150 \mathrm{~B} / \mathrm{Day}$ \\
\hline
\end{tabular}

\subsection{Mathematical Model}

The development of reservoir simulators starts with formulation of finite difference model for the mathematical equations that govern the flow of fluid in porous media. These mathematical equations describes the physical processes of interest in the reservoir and are in the form of PDEs that takes into account the dynamic relationship between the fluid, the porous medium and the system's flow conditions (Ertekin et al., 2007). These PDEs are formulated by obeying the three main physical principles, such as continuity equation, Darcy's law and equation of state. The general form of single-phase fluid flow equation is given as:

$$
\frac{\partial}{\partial x}\left(\frac{\beta_{c} A_{x} k_{x}}{\mu B} \frac{\partial \Phi}{\partial x}\right) \Delta x+\frac{\partial}{\partial y}\left(\frac{\beta_{c} A_{y} k_{y}}{\mu B} \frac{\partial \Phi}{\partial y}\right) \Delta y+\frac{\partial}{\partial z}\left(\frac{\beta_{c} A_{z} k_{z}}{\mu B} \frac{\partial \Phi}{\partial z}\right) \Delta z+q_{s c}=\frac{V_{b}}{\alpha_{c}} \frac{\partial}{\partial t}\left(\frac{\phi}{B}\right)
$$


Based on the problem at hand, Eq. (1) is simplified using the underlying assumptions below to yield:

$$
\frac{\partial}{\partial x}\left(\frac{\beta_{c} A_{x} k_{x}}{\mu B} \frac{\partial P}{\partial x}\right) \Delta x+q_{s c}=\frac{v_{b}}{\alpha_{c}}\left(\frac{\phi}{B}\right) C_{t} \frac{\partial P}{\partial t}
$$

\subsubsection{Basic Assumptions}

- Isothermal reservoir; temperature remains constant

- Homogenous reservoir with block-centered grid system

- Horizontal fluid flow; gravitational force in the $\mathrm{z}$ direction can be ignored

- One dimensional flow; flow terms in both y and $\mathrm{z}$ directions are neglected

- Constant oil viscosity and density

- Uniform grid size

- No-flow reservoir boundary condition

\subsection{Numerical Reservoir Simulation}

According to Mustafiz and Islam (2008), solving Eq. (2) analytically (exactly), would only yield pressure, fluid saturation, and production rates as continuous functions of time and location. Abou-Kassem et al. (2006) asserts that, analytical methods tends to yield precise solutions to simplified problems, while numerical methods provide approximate solutions to exact problems. Therefore, due to the nonlinear nature of the equation, analytical techniques cannot be used and therefore solutions must be obtained with numerical methods. Detailed information about the numerical methods including finite difference, finite volume and finite element can be found in Chen et al. (2006). Numerical solutions provide pressure and saturation values only at discrete points in the reservoir (Islam et al., 2016). Therefore, discretization aids in converting the PDEs in Eq. (2) into algebraic equations by employing known methods such as Taylor series, the integral method and the variational method (Aziz and Setari, 1979). Among the notable fluid flow discretization methods, the widely employed approach in the petroleum industry is the finitedifference method (Hossain, 2010) because it is simple, and can be extended from one-dimensional (1D) to three-dimensional (3D) as well as compatible with multiphase flow (Firoozabadi et al., 2006). Yet, the equations provided by the discretization process are nonlinear and impossible to obtain solution using algebraic approach, therefore they must be linearized before solutions can be attained (Hossain, 2010) by utilization any of the known linear solver techniques (Abou-Kassem, 2007). The two main linear solver techniques are direct and iterative methods.

\subsubsection{Direct Methods}

The direct methods provides an exact solution after a finite number of mathematical operations performed without round-off errors. Some of the direct methods include Gaussian elimination method, Lower Upper (LU) factorization, and the Gauss-Jordan method (Martynenko, 2017). However, the direct methods are suitable for smaller problems, where an exact solution is possible but not for very large sparse problems where excessive run times are essential (Sood, 2016).

\subsubsection{Iterative Methods}

In iterative methods, an initial guess is used to obtain an approximation to the solution namely the conjugate gradient method, the Gauss-Siedel method, Jacobi's method among others (Ertekin et al., 2007). The effectiveness of these solvers relies on the properties of the problem at hand and the preconditioning. Furthermore, they are economical than the direct solver scheme because less memory and fewer flops are required in their computations. However, solutions with multiple right hand sides can be challenging (Sood, 2016).

\subsection{Numerical Model Derivation and Solution}

The equation constituting the mathematical model of the reservoir is too complex to be solved by analytical method, therefore, the problem is solved in a reservoir modelling so as to advance the simulation from the initial condition to future times. This can be achieved by stepping through the simulation by choosing discrete time intervals called time steps (Aphu et al., 2018). Therefore, finite difference approximation enables the representation of equations in a format that is solvable by a digital computer. The fundamental idea of finite difference method is to substitute the partial derivatives approximations attained by Taylor expansions closer to the point of interest. In that regard, any of the two main finite difference schemes (explicit or implicit method) can be used to discretize the equations.

\subsubsection{Implicit Backward-Difference Formulation}

The backward finite-difference approximation to slightly compressible flow results in an implicit calculation procedure for the new time level pressure. Hence it is used to find solutions by solving an equation involving both the current state of the system and in the later time. The procedure of implicit finite-difference formulation is illustrated by the following steps;

- Solving Eq. (2), by expressing its left hand side (LHS) first term in an implicit form gives: 


$$
\frac{\partial}{\partial x}\left(\frac{\beta_{c} A_{x} k_{x}}{\mu B} \frac{\partial P}{\partial x}\right) \Delta x \approx\left(\frac{\beta_{c} A_{x} k_{x}}{\mu B} \frac{\partial P}{\partial x}\right)_{i+\frac{1}{2}}-\left(\frac{\beta_{c} A_{x} k_{x}}{\mu B} \frac{\partial P}{\partial x}\right)_{i-\frac{1}{2}}
$$

Expanding the right hand side (RHS) terms of Eq. (3) and expressing them in implicit backward-difference form gives:

$$
\frac{\partial}{\partial x}\left(\frac{\beta_{c} A_{x} k_{x}}{\mu B} \frac{\partial P}{\partial x}\right) \Delta x=\left(\frac{\beta_{c} A_{x} k_{x}}{\mu B}\right)_{i+\frac{1}{2}}\left(\frac{\partial P}{\partial x}\right)_{i+\frac{1}{2}}-\left(\frac{\beta_{c} A_{x} k_{x}}{\mu B}\right)_{i-\frac{1}{2}}\left(\frac{\partial P}{\partial x}\right)_{i-\frac{1}{2}}
$$

Expansion of Eq. (4) in fully implicit form gives:

$$
\frac{\partial}{\partial x}\left(\frac{\beta_{c} A_{x} k_{x}}{\mu B} \frac{\partial P}{\partial x}\right) \Delta x=\left(\frac{\beta_{c} A_{x} k_{x}}{\mu B}\right)_{i+\frac{1}{2}} P_{i+1}^{n+1}-\left[\left(\frac{\beta_{c} A_{x} k_{x}}{\mu B}\right)_{i+\frac{1}{2}}+\left(\frac{\beta_{c} A_{x} k_{x}}{\mu B}\right)_{i-\frac{1}{2}}\right] P_{i}^{n+1}+\left(\frac{\beta_{c} A_{x} k_{x}}{\mu B}\right)_{i-\frac{1}{2}} P_{i-1}^{n+1}
$$

Expressing the change in pressure term over time in the RHS of Eq. (2) in the implicit form yields:

$$
\frac{\partial P}{\partial t}=\frac{P_{i+1}^{n+1}-P_{i}^{n}}{\Delta t}
$$

Substituting Eqs. (5) and (6) into the Eq. (2) gives:

$$
\left(\frac{\beta_{c} A_{x} k_{x}}{\mu B \Delta x}\right)_{i+\frac{1}{2}} P_{i+1}^{n+1}-\left[\left(\frac{\beta_{c} A_{x} k_{x}}{\mu B \Delta x}\right)_{i+\frac{1}{2}}+\left(\frac{\beta_{c} A_{x} k_{x}}{\mu B \Delta x}\right)_{i-\frac{1}{2}}\right] P_{i}^{n+1}+\left(\frac{\beta_{c} A_{x} k_{x}}{\mu B \Delta x}\right)_{i-\frac{1}{2}} P_{i-1}^{n+1}+q_{s c}=\frac{V_{b} \phi C_{t}}{\alpha_{c} B \Delta t}\left(P_{i+1}^{n+1}-P_{i}^{n}\right)
$$

The backward-difference approximation to the slightly compressible flow Eq. (2) results in an implicit calculation procedure for the new-time-level pressures. The quantities $P_{i+1}^{n+1}, P_{i}^{n+1}, P_{i-1}^{n+1}$ are all unknown parameters. They cannot be solved explicitly for $P_{i}^{n+1}$ because both $P_{i+1}^{n+1}$ and $P_{i-1}^{n+1}$ are also unknown. Subsequently, Eq. (7) is solved for all the 10 gridblock and the unknowns simultaneously.

- Solve Writing Eq. (7) in notational form can be presented in Table 2 as:

Table 2. Notational Representation

\begin{tabular}{ccc}
\hline \multicolumn{3}{c}{ Direction } \\
\hline $\mathrm{W}$ & $\mathrm{C}$ & $\mathrm{E}$ \\
$i-1$ & $i$ & $i+1$ \\
\hline
\end{tabular}

Applying the notation, Eq. (7) becomes:

$$
W_{i} P_{i-1}^{n+1}+C_{i} P_{i}^{n+1}+E_{i} P_{i+1}^{n+1}=Q_{i}
$$

Where $W_{i}, C_{i}$ and $E_{i}$ are the coefficients of pressures $P_{i-1}^{n+1}, P_{i}^{n+1}$ and $P_{i+1}^{n+1}$ respectively with $\mathrm{W}$ and $\mathrm{E}$ being the directions, West and East respectively of grid cell $i(i=1,2,3 \ldots 10$ for gridblock 1 to 10 respectively) whose centre is $\mathrm{C}$. The individual parts in Eq. (8) can be expressed as:

$$
W_{i}=\left(\frac{\beta_{c} \mathrm{~A}_{x} k_{x}}{\mu \mathrm{B} \Delta x}\right)_{i-\frac{1}{2}}
$$




$$
\begin{aligned}
C_{i} & =\left[\left(\frac{\beta_{c} \mathrm{~A}_{x} k_{x}}{\mu \mathrm{B} \Delta x}\right)_{i-\frac{1}{2}}+\left(\frac{\beta_{c} \mathrm{~A}_{x} k_{x}}{\mu \mathrm{B} \Delta x}\right)_{i+\frac{1}{2}}+\left(\frac{\beta_{c} \mathrm{~A}_{x} k_{x}}{\mu \mathrm{B} \Delta x}\right)_{i}\right] \\
E_{i} & =\left(\frac{\beta_{c} \mathrm{~A}_{x} k_{x}}{\mu \mathrm{B} \Delta x} \frac{\partial P}{\partial x}\right)_{i+\frac{1}{2}} \\
Q_{i} & =\left(\frac{v_{b} \phi C_{t}}{\alpha_{c} \mathrm{~B} \Delta t}\right)_{i} P_{i}^{n}-q_{s c_{i}}
\end{aligned}
$$

- Applying initial and boundary conditions

Initial condition: $P(i, 0)=6000$ psia (at time-level, $\mathrm{n}=0$; pressures $P_{i}^{n}=6000$ psia at all gridblocks)

Boundary condition: $\frac{\partial P}{\partial x}=0$ both at the left and right boundary; gridblock 1 and 10 respectively.

Approximating the left boundary condition using central difference gives:

$$
\frac{P_{i}-P_{0}}{x_{i}-x_{0}}=0 ; \frac{P_{i}-P_{0}}{\Delta x}=0 ; P_{i}=P_{0}
$$

Similarly, applying central difference at the right boundary yields:

$$
\frac{P_{11}-P_{10}}{x_{11}-x_{10}}=0 ; \frac{P_{11}-P_{10}}{\Delta x}=0 ; P_{11}-P_{10}
$$

- Writing Eq. (7) for each gridblock using Eq. (8) gives a matrix representation in the form:

$$
\left[\begin{array}{cccccccccc}
\left(C_{1}+W_{1}\right) & E_{1} & 0 & 0 & 0 & 0 & 0 & 0 & 0 & 0 \\
W_{2} & C_{2} & E_{2} & 0 & 0 & 0 & 0 & 0 & 0 & 0 \\
0 & W_{3} & C_{3} & E_{3} & 0 & 0 & 0 & 0 & 0 & 0 \\
0 & 0 & W_{4} & C_{4} & E_{4} & 0 & 0 & 0 & 0 & 0 \\
0 & 0 & 0 & W_{5} & C_{5} & E_{5} & 0 & 0 & 0 & 0 \\
0 & 0 & 0 & 0 & W_{6} & C_{6} & E_{6} & 0 & 0 & 0 \\
0 & 0 & 0 & 0 & 0 & W_{7} & C_{7} & E_{7} & 0 & 0 \\
0 & 0 & 0 & 0 & 0 & 0 & W_{8} & C_{8} & E_{8} & 0 \\
0 & 0 & 0 & 0 & 0 & 0 & 0 & W_{9} & C_{9} & E_{9} \\
0 & 0 & 0 & 0 & 0 & 0 & 0 & 0 & W_{10} & \left(C_{10}+W_{10}\right)
\end{array}\right]\left[\begin{array}{c}
P_{1}^{n+1} \\
P_{2}^{n+1} \\
P_{3}^{n+1} \\
P_{4}^{n+1} \\
P_{5}^{n+1} \\
P_{6}^{n+1} \\
P_{7}^{n+1} \\
P_{8}^{n+1} \\
P_{9}^{n+1} \\
P_{10}^{n+1}
\end{array}\right]=\left[\begin{array}{c}
Q_{1} \\
Q_{2} \\
Q_{3} \\
Q_{4} \\
Q_{5} \\
Q_{6} \\
Q_{7} \\
Q_{8} \\
Q_{9} \\
Q_{10}
\end{array}\right]
$$

A computer program was then written in MATLAB environment applying iterative linear solver technique to solve for the unknown pressures.

\subsubsection{Explicit Forward-Difference Formulation}

The forward-difference approximation to slightly compressible flow results in explicit calculation procedure for later time from the state of the system at current time. Here all terms on the one side are known because all pressures appearing on this side are at the known old time level, $n$. The new time pressures can be obtained explicitly by the use of these known pressures. The forwarddifference approximation to the flow Eq. (2) results in an explicit calculation procedure for the new-time-level pressures (designated as $n+1$ in the finite-difference equations). The forward-difference for the unknown quantity $P_{i}^{n+1}$ is solved for as follows:

- Expressing Eq. (2) in an explicit finite-difference form by recalling Eq. (3) and (4) becomes: 


$$
\frac{\partial}{\partial x}\left(\frac{B_{c} A_{x} k_{x}}{\mu B} \frac{\partial P}{\partial x}\right) \Delta x=\left(\frac{B_{c} A_{x} k_{x}}{\mu B \Delta x}\right)_{i+\frac{1}{2}}\left(P_{i+1}^{n}-P_{i}^{n}\right)-\left(\frac{B_{c} A_{x} k_{x}}{\mu B \Delta x}\right)_{i-\frac{1}{2}}\left(P_{i}^{n}-P_{i-1}^{n}\right)_{i-\frac{1}{2}}
$$

Expanding Eq. (16) yields:

$$
\frac{\partial}{\partial x}\left(\frac{\beta_{c} A_{x} k_{x}}{\mu B} \frac{\partial P}{\partial x}\right) \Delta x=\left(\frac{\beta_{c} A_{x} k_{x}}{\mu B \Delta x}\right)_{i+\frac{1}{2}} P_{i+1}^{n}-\left[\left(\frac{\beta_{c} A_{x} k_{x}}{\mu B \Delta x}\right)_{i+\frac{1}{2}}+\left(\frac{\beta_{c} A_{x} k_{x}}{\mu B \Delta x}\right)_{i-\frac{1}{2}}\right] P_{i+1}^{n}+\left(\frac{\beta_{c} A_{x} k_{x}}{\mu B \Delta x}\right)_{i-\frac{1}{2}} P_{i-1}^{n}
$$

The change in pressure over time term in the RHS of Eq. (2) can be expressed in explicit form as:

$$
\frac{\partial P}{\partial t}=\frac{P_{i}^{n+1}-P_{i}^{n}}{\Delta t}
$$

Substituting Eqs. (17) and (18) into Eq. (2) gives:

$$
P_{i}^{n+1}=P_{i}^{n}+\left(\frac{\alpha_{c} B \Delta t}{V_{b} \phi C_{t}}\right)_{i} q_{s c_{i}}+\left(\frac{\alpha_{c} B \partial t}{V_{b} \phi C_{t}}\right)_{i}\left[\left(\frac{\beta_{c} A_{x} k_{x}}{\mu B \Delta x}\right)_{i+\frac{1}{2}} P_{i+1}^{n}-\left[\left(\frac{\beta_{c} A_{x} k_{x}}{\mu B \Delta x}\right)_{i+\frac{1}{2}}+\left(\frac{\beta_{c} A_{x} k_{x}}{\mu B \Delta x}\right)_{i-\frac{1}{2}}\right] P_{i}^{n}+\left(\frac{\beta_{c} A_{x} k_{x}}{\mu B \Delta x}\right)_{i-\frac{1}{2}} P_{i-1}^{n}\right]
$$

Expressing Eq. (19) in terms of transmissibility gives:

$$
P_{i}^{n+1}=P_{i}^{n}+\left(\frac{\alpha_{c} B \Delta t}{V_{b} \phi C_{t}}\right)_{i} q_{s c_{i}}+\left(\frac{\alpha_{c} B \Delta t}{V_{b} \phi C_{t}}\right)_{i}\left[T_{i x_{i+\frac{1}{2}}} P_{i+1}^{n}-\left(T_{i x_{i+\frac{1}{2}}}+T_{i x_{i-\frac{1}{2}}}\right) P_{i}^{n}+T_{i x_{i-\frac{1}{2}}} P_{i-1}^{n}\right]
$$

Where $\quad T_{i x_{i+\frac{1}{2}}}=T_{i x_{i-\frac{1}{2}}}=\frac{B_{c} A_{x} k_{x}}{\mu B \Delta x}$

As shown in Eq. (20), all terms on the right side of the equation are known because all pressures appearing on this side are at the known (old) time level, $n$. In this equation, the pressures at the new-time level, $n+l$ can be obtained explicitly by the use of these known pressures.

- The same boundary and initial conditions for the implicit method was repeated.

- The unknown pressure for each gridblocks were obtained using computer program in MATLAB from the start to the end of the simulation (i.e. 360 days)

\section{Results and Discussion}

\subsection{Explicit Forward Difference Method}

Figure 3 shows the pressure distribution throughout the year for explicit method using timestep of 1 day. From Figure 3, it is evident that the pressure at gridblock 1 which is at the left boundary remained unchanged from the start of the simulation (i.e. day 1) to day 3 and started declining from timestep of day 4. This is because, during this period, the pressure transient from the producing well (cell block 4) due to fluid withdrawal has not yet been felt at the left boundary as it moves one gridblock per each timestep. From day 4 onwards, a decline in pressure was observed indicating that the pressure propagation has reached the boundary, although pressure keeps declining but in a way that is slow and steady. On the contrary, the pressure at gridblock 10 which is at the right boundary remained unchanged from the start of the simulation up to day 9 . This condition can be attributed to the fact that, the producing well is far from the right boundary ( 5 cell blocks interval) compared to the left boundary which is only two block apart therefore taking the pressure propagation longer time ( 10 days) to reach the right boundary. With regards to gridblock 3 and 5 which is in close proximity with the producing well, there is a constant decline of pressure from day 2 to 7 and then slight change in pressure until the simulation ends. The reason for this phenomena is due to their adjacent placement with gridblock 4 hence almost equal pressure drop is felt during fluid withdrawal. Consequently, it can be inferred that, the closer the 
gridblock is to the producing well, the higher the pressure drop during fluid withdrawal. This is as result of the shorter time required for the pressure propagation to reach these gridblock close to the producing well. This can be clearly seen in the simulation results for gridblock 1,2 , and 6 to 10 .

Although a steady pressure decline was seen in Figure 3, the simulation recorded negative pressures for gridblocks 1 to 6 starting at simulation time of day 268 for gridblock 4, followed by gridblock 3 at day 288, and then day 301, 307, 308 and 340 for gridblocks 2, 5, 1 and 6 respectively. This trend was not seen in gridblocks 7 to 10 due to the wide distance between the producing well and these gridblocks making the pressure transient felt at the extreme end of the gridblock to be minimal. Nevertheless, lower values were recorded for gridblocks 7 to 10 at the end of the simulation; this means increasing the simulation time beyond 360 days would eventually result in negative values. Besides, the negative values recorded is not realistic for the nature of problem being solved. Therefore, different timestep of 2 and 3 days was chosen and the simulation was repeated in order to investigate the behaviour of the pressure distribution of pressure at these timesteps. The simulation results using timestep 2 and 3 days gave quite a satisfactory outcome as shown in Figure 4 and 5 respectively. Even though with timestep of 2 and 3, the explicit method gave acceptable results but the pressure decline was not consistent making it difficult to decide on which of the results fully describes the problem at hand. The simulation results comparing the different timesteps revealed that the stability of the explicit finite difference formulation is contingent on specific conditions be it the chosen timestep, gridblock size, reservoir geometry or the allocated simulation time. This is a major limitation of the explicit forward-difference formulation thereby rendering it usage less in petroleum reservoir simulation. The 3D view of the pressure distribution are also illustrated by Figure 6,7 and 8 for timestep of 1,2 and 3 days respectively.

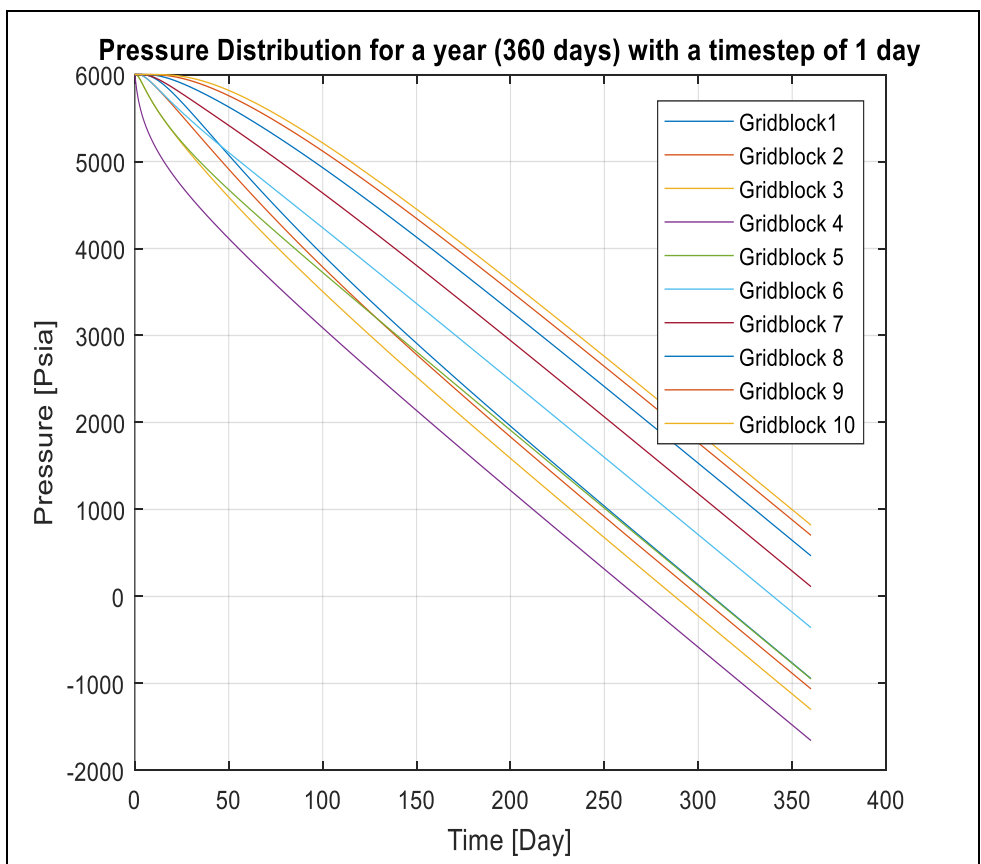

Figure 3. Pressure distribution for a year with a timestep of 1 day with explicit method

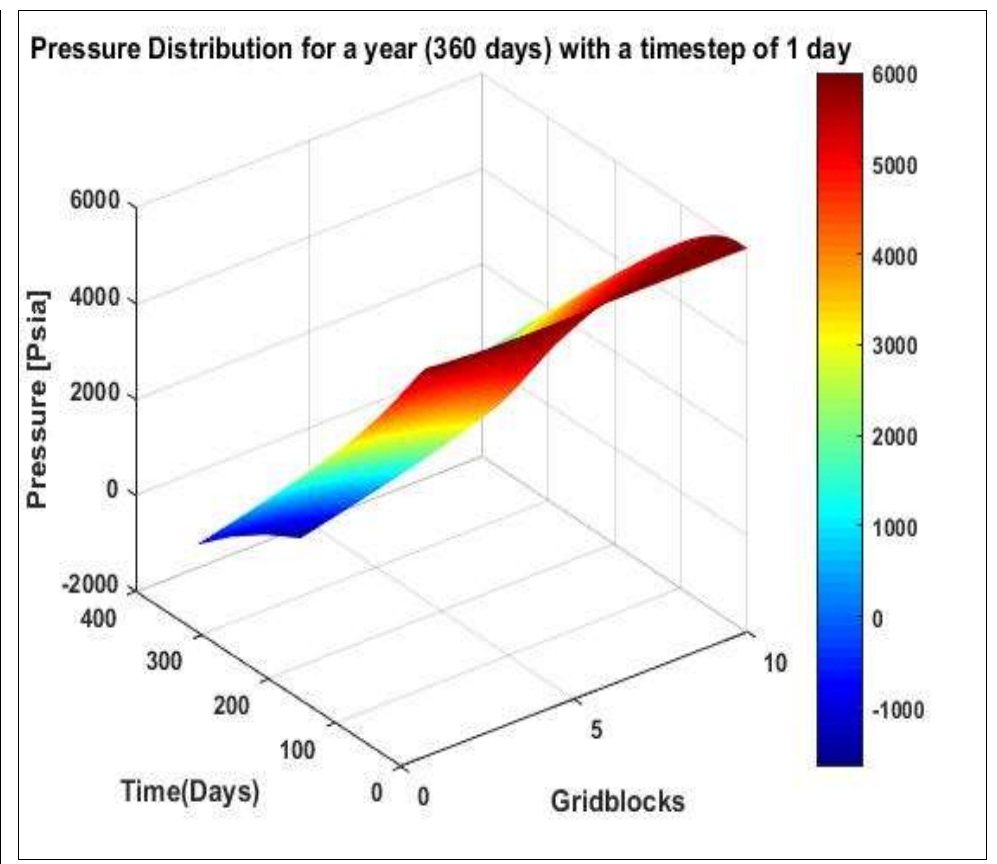

Figure 6. 3D view of pressure distribution for a year with a timestep of 1 day using explicit method 


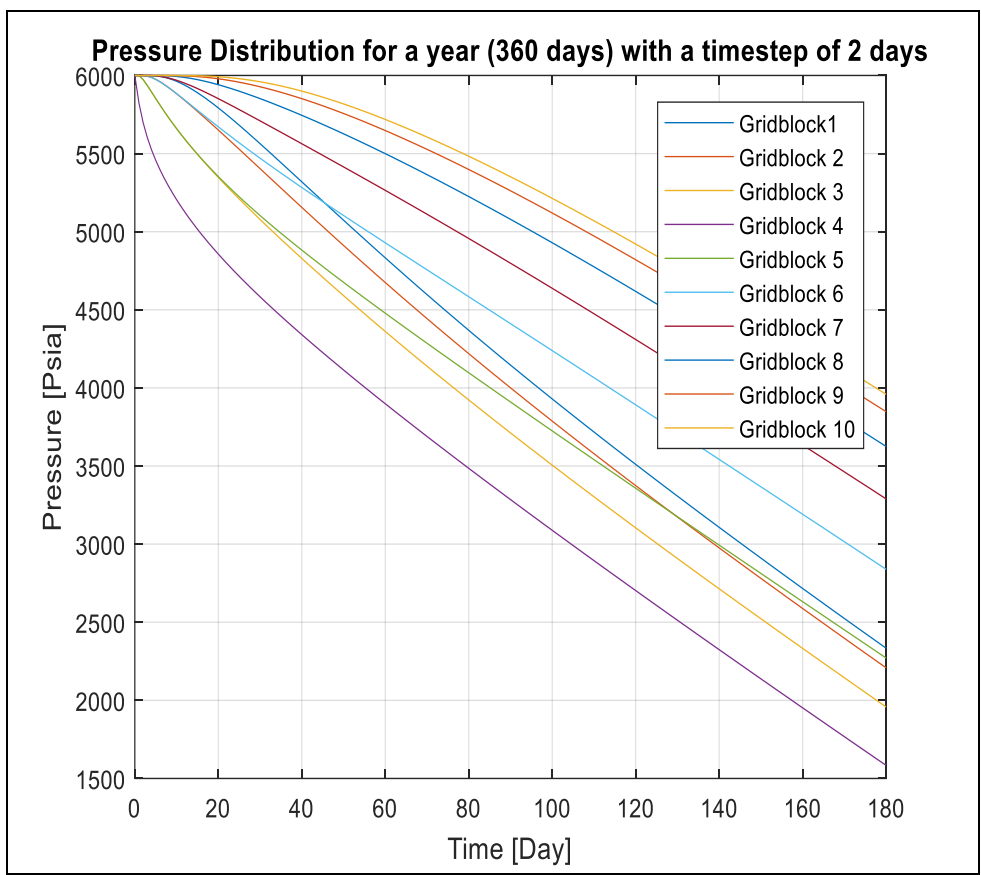

Figure 4. Pressure distribution for a year with a timestep of 2 days with explicit method

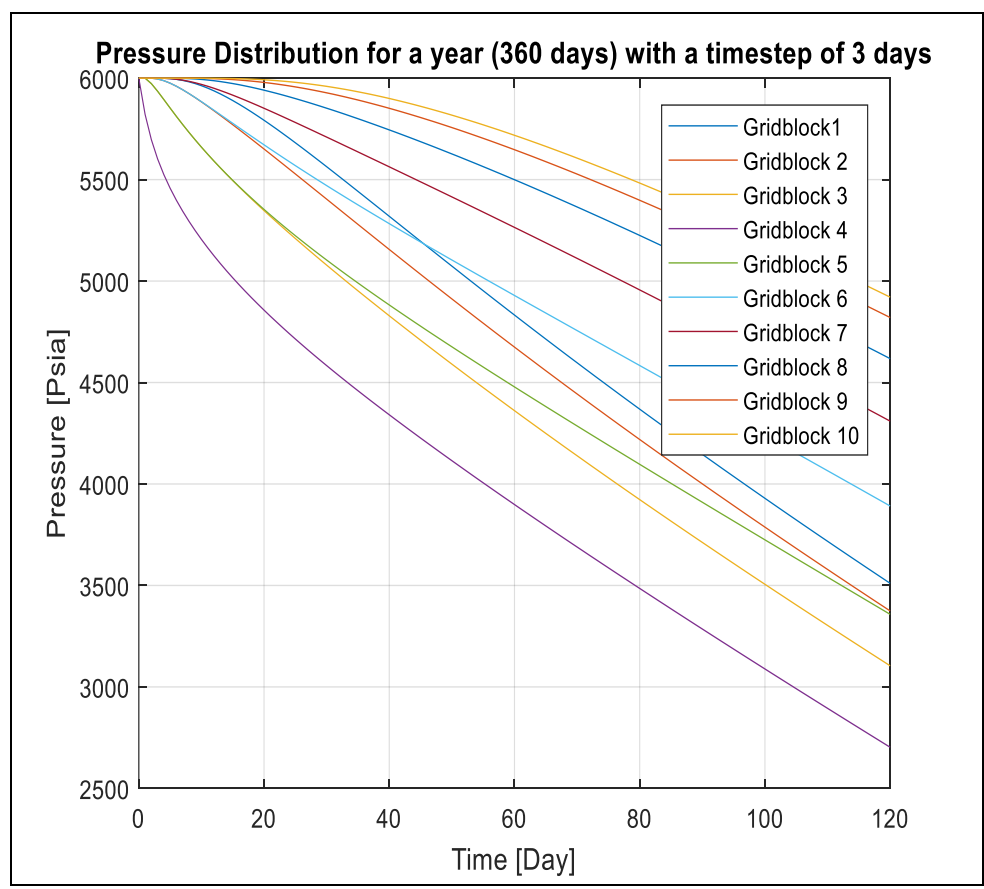

Figure 5. Pressure distribution for a year with a timestep of 3 days using explicit method

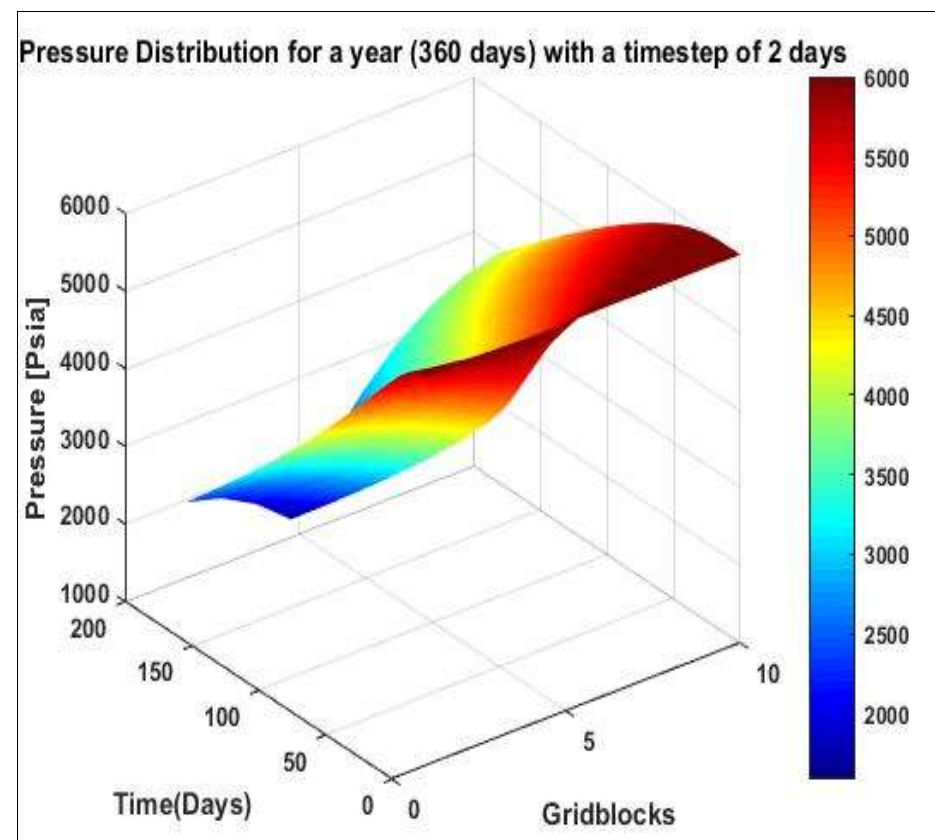

Figure 7. 3D view of pressure distribution for a year with a timestep of 2 days using explicit method

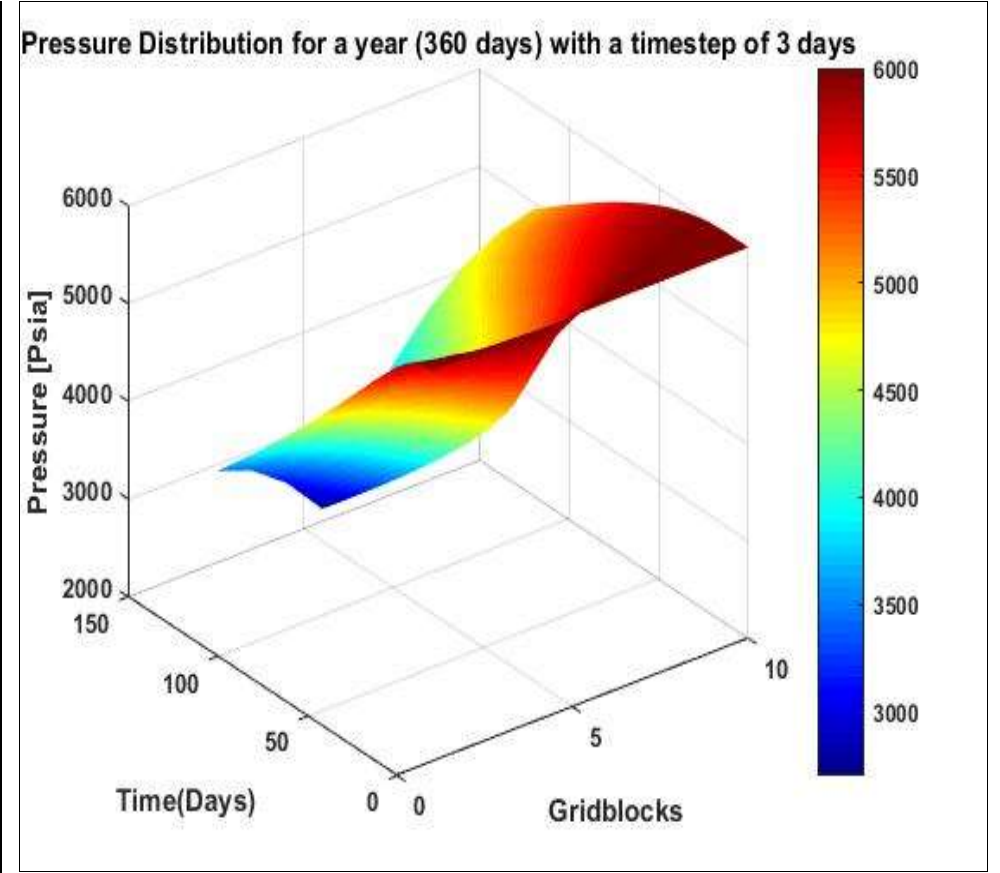

Figure 8. 3D view of pressure distribution for a year with a timestep of 3 days using explicit method

\subsection{Implicit Backward Difference Method}

As in the case of the explicit method, Figure 9 depicts the results of simulations obtained for implicit method using the same timestep size of 1 day. Unlike the explicit finite difference formulation where the pressure move one gridblock per each timestep, in implicit method the pressure can move more than one gridblock per each timestep. This is quite obvious in Figure 9 as the pressure decline was seen not only at gridblock 4 at day 1 as in the explicit method, but there was also a decrease in pressure at gridblock 3 and 5 for simulation time of 1 day. This is because, the implicit method requires solving unknown pressures for couple of systems of equations as shown in the matrix representation in (Eq. 15). Similarly, the implicit method showed the same gradual decrease in pressure first at the adjacent blocks because of their closeness to the producing well (gridblock 4) and then moved out 
to the nearby blocks, thereby affirming the statement, the nearer the gridblock is to the producing well, the higher the pressure drop during fluid withdrawal. This could be the short time the pressure transient takes to reach these gridblocks close to the producing well. Correspondingly, gridblock 3 and 5 depicted the same trend (constant pressure values) as indicated in the simulation results of the explicit method but it took a longer simulation time (day 52) before there was a slight and steady change in the respective pressure values. For gridblock 2 and 6, the same pressure values were recorded from day 1 to day 45, then a decline was seen from day 46 forward. The perfect trend that was observed maybe due to their placement side-by-side with gridblock 3 and 5 respectively, therefore less pressure disturbance due to fluid withdrawal. However, the change in their respective pressure values can be ascribed to the pressure disturbances occurring at the immediate gridblocks (gridblock 1 and 7) due to fluid withdrawal.

Comparatively, gridblock 1 and 7 recorded the same trend (constant pressure values) as seen in gridblock 2 and 6 from the start of the simulation until a decline at day 25. The slight difference in their pressure values is because of the pressure transient reaching gridblock 8 at day 25 , hence a causing a drop in pressure for the first time at gridblock 8 . On the other hand, a smooth pressure decline was also seen in gridblocks 8 and 9 due to their wide distance from the producing well. However, the gridblock 10 which on the right boundary maintained a constant pressure from simulation time of 1 day until a decline was seen on day 63 , a trend that was not seen in the simulation results of the explicit formulation. Unlike the explicit method, even for a timestep less than 1 day (3, 6 and 12 hours), a quite satisfactory result was obtained for the implicit method. Similar trend (acceptable results) was also observed for the implicit method using timestep of 2 and 3 days as depicted in Figure 10 and 11 respectively. This demonstrates the sturdiness of the implicit finite difference formulation over that of the explicit difference formulation at different simulation conditions. In general, the simulation results of the implicit backward difference formulation and explicit forward difference formulation gave disparate result even when the same timestep was used. This can be credited to the approximate nature of finite difference approach. It is worth mentioning that, the implicit backward difference formulation is unconditionally stable, in other words it is impossible for the formulation to exhibit any unstable behaviour regardless of the timestep or gridblock size. However, this condition is not always suitable as large timesteps and block sizes may result in impractical approximations. Even with this limitation, Ertekin et al. (2007), affirms that because the implicit backward formulation is stable unconditionally, it is the widely used formulation in petroleum reservoir simulation. The 3D view of the pressure distribution along the horizontal gridblock 1 to 10 with timestep of 1,2 and 3 days are illustrated by Figure 12,13 and 14 respectively.

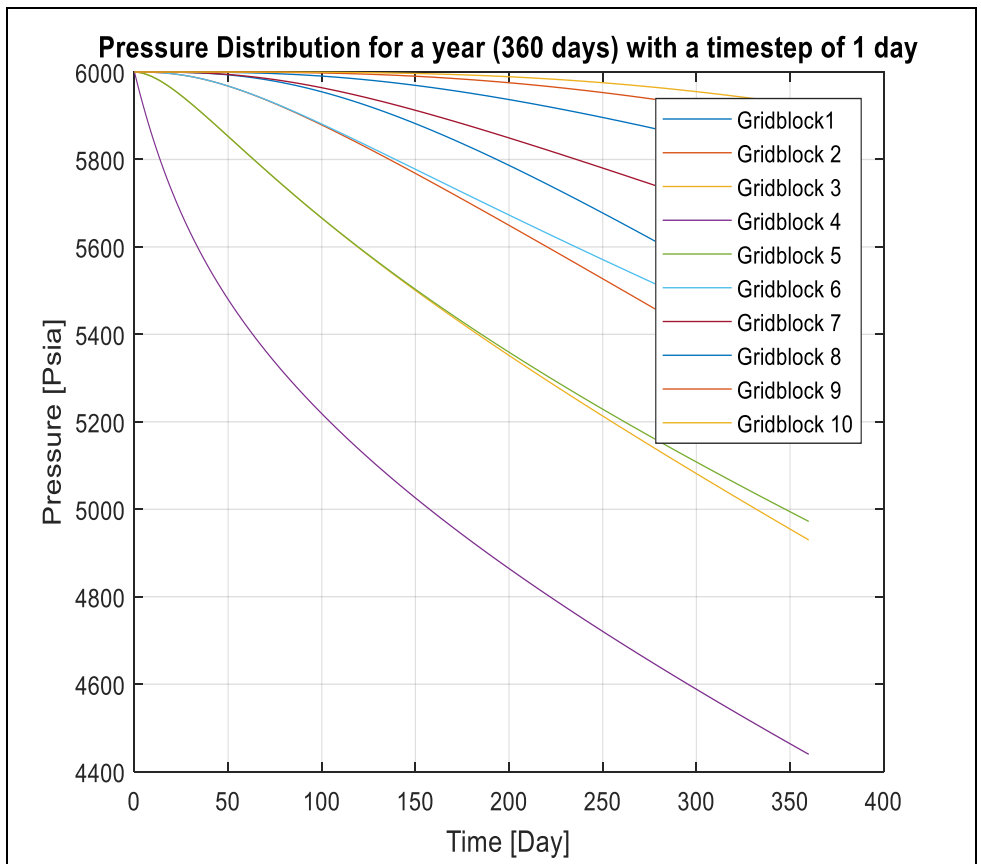

Figure 9. Pressure distribution for a year with a timestep of 1 day using implicit method

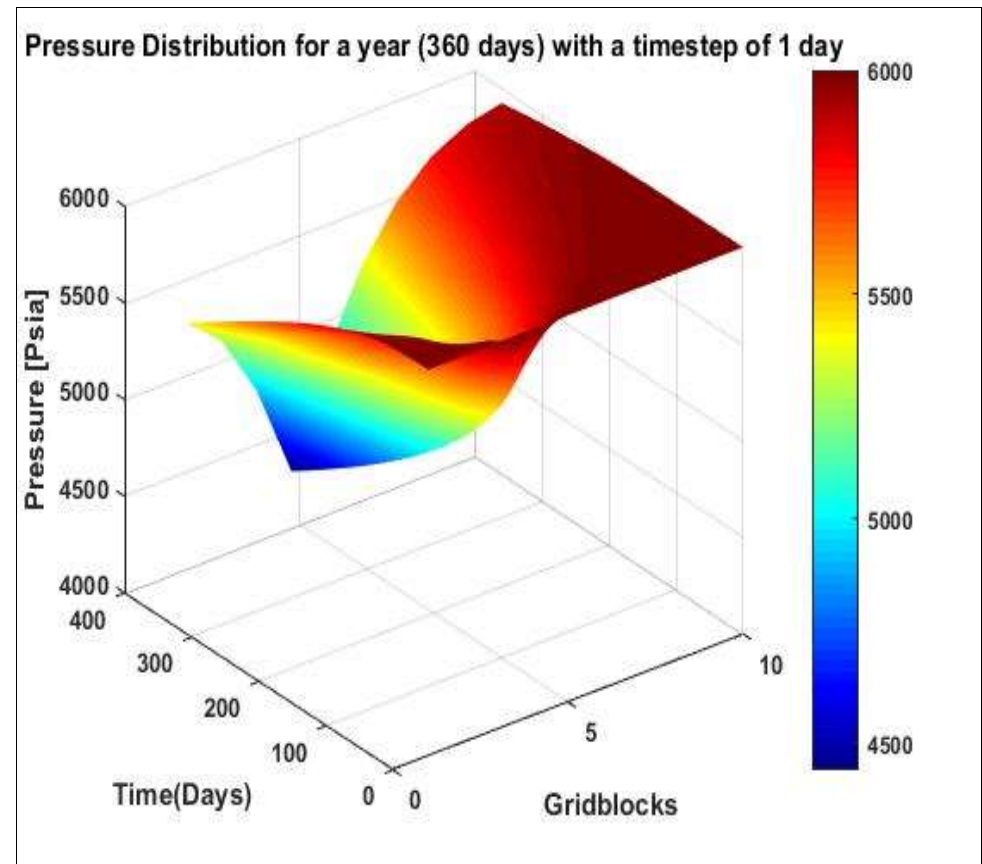

Figure 12. 3-D view of pressure distribution for a year with a timestep of 1 day using implicit method 


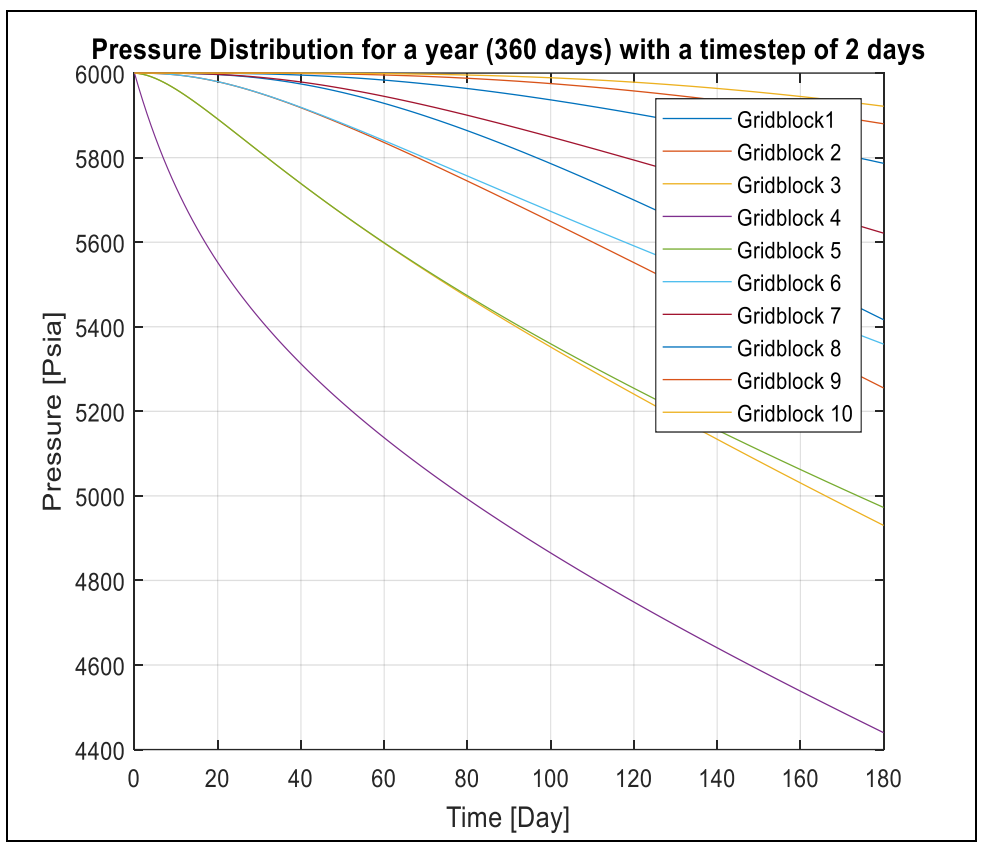

Figure 10. Pressure distribution for a year with a timestep of 2 days using implicit method

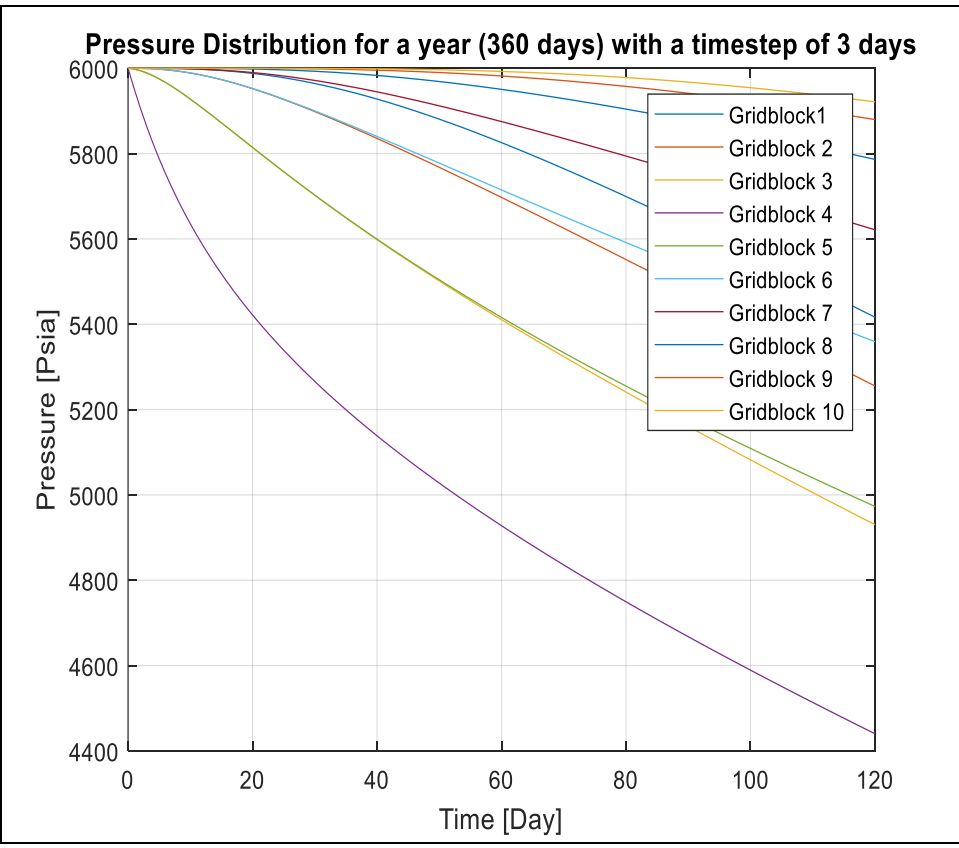

Figure 11. Pressure distribution for a year with a timestep of 3 days using implicit method

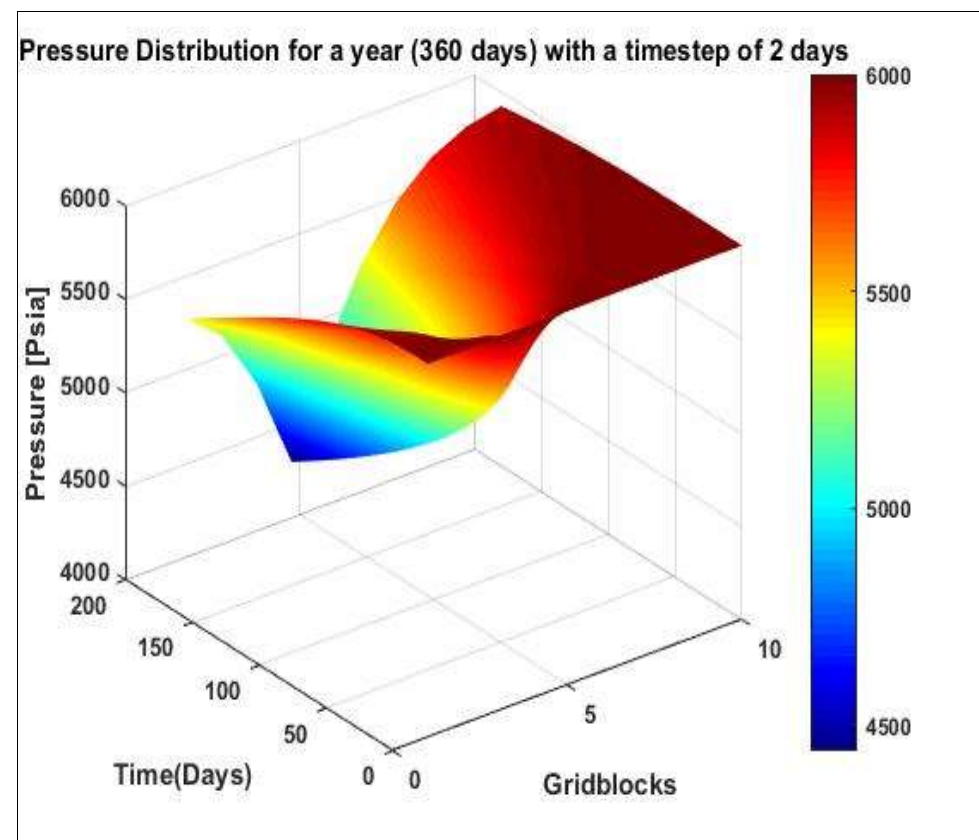

Figure 13. 3D view of pressure distribution for a year with a timestep of 2 days using implicit method

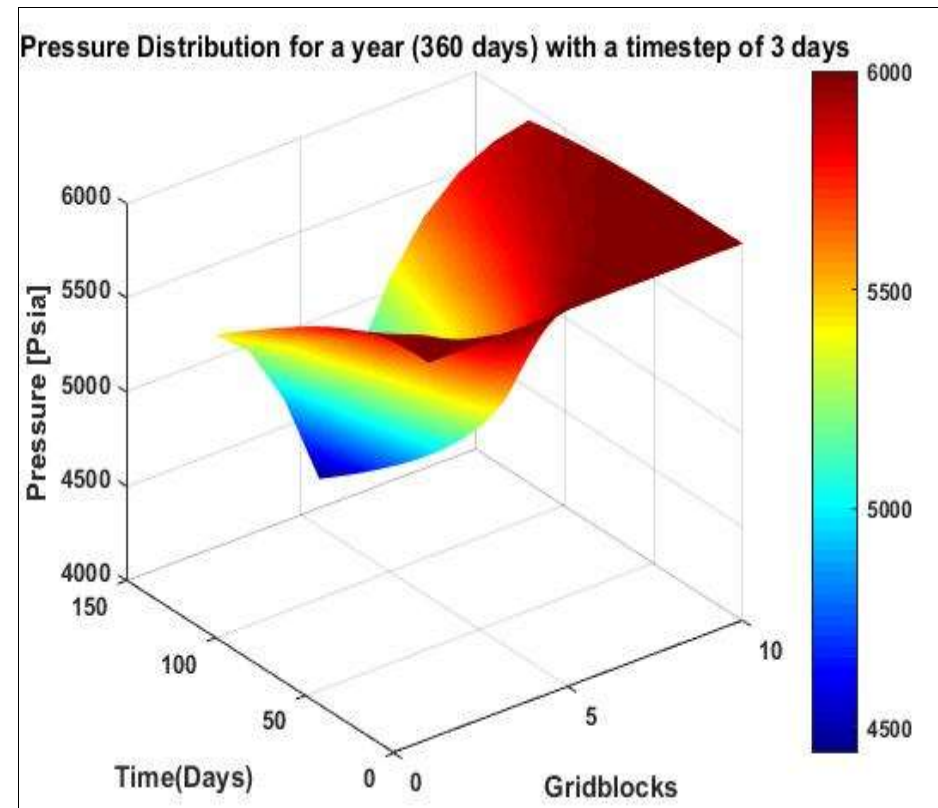

Figure 14. 3-D view of pressure distribution for a year with a timestep of 3 days using implicit method

\subsection{Numerical Results Validation}

Numerical solutions to fluid flow equations provided by computer programming languages such as MATLAB require validation of the simulation results either through analytical means or by the use of available commercial software so as to fully affirm the soundness of the simulation results upon which major decisions about reservoir monitoring and management would be based. In view of these, the simulation results obtained after implementation of the explicit and implicit method to predict the pressure distribution in the aforementioned target reservoir were validated by building a one-dimensional single phase flow model (black oil) in a commercial Computer Modeling Group (CMG) software. The data in Table 1 together with the underlying assumptions were considered in building the model. A time step of 1 day was chosen and the simulation was run from January 1, 2018 to December 27, 2018 amounting to total simulation time of 360 days same as the time frame used in the explicit and implicit method. Figure 15 shows the pictorial view of the one-dimensional reservoir model built using the commercial simulator. 
After a successful simulation run, the producing well (gridblock 4) pressure profile generated by the simulator was compared with that of the implicit results generated by the numerical codes. The reason for comparing the implicit results with that of the simulator was because of the satisfactory results attained after the method implementation. Additionally, the commercial software used has an in-built fully implicit scheme thereby making the choice of comparison a reasonable one. Figure 16 depicts the comparison of pressure values generated by the simulator and the numerical codes using a timestep of 1 day as a case study. At day 1, there was no change in pressure values for both curves until day 7 where changes in the pressure values was witnessed. After day 7, a slight changes in the pressure profile for both pressure curves continued until a close match was observed at day 240 and through to the end of the simulation time (i.e.360 days). It is worth mentioning that, even though the same input data (Table 1) as used in both the explicit and implicit formulation was used in the simulator, the slight changes in the curves (Figure 16), could be due to numerical dispersion error term associated with finite difference approximations. Overall, a satisfactory match was observed between the two pressure profiles thereby affirming the validity of the results obtained from the numerical code.

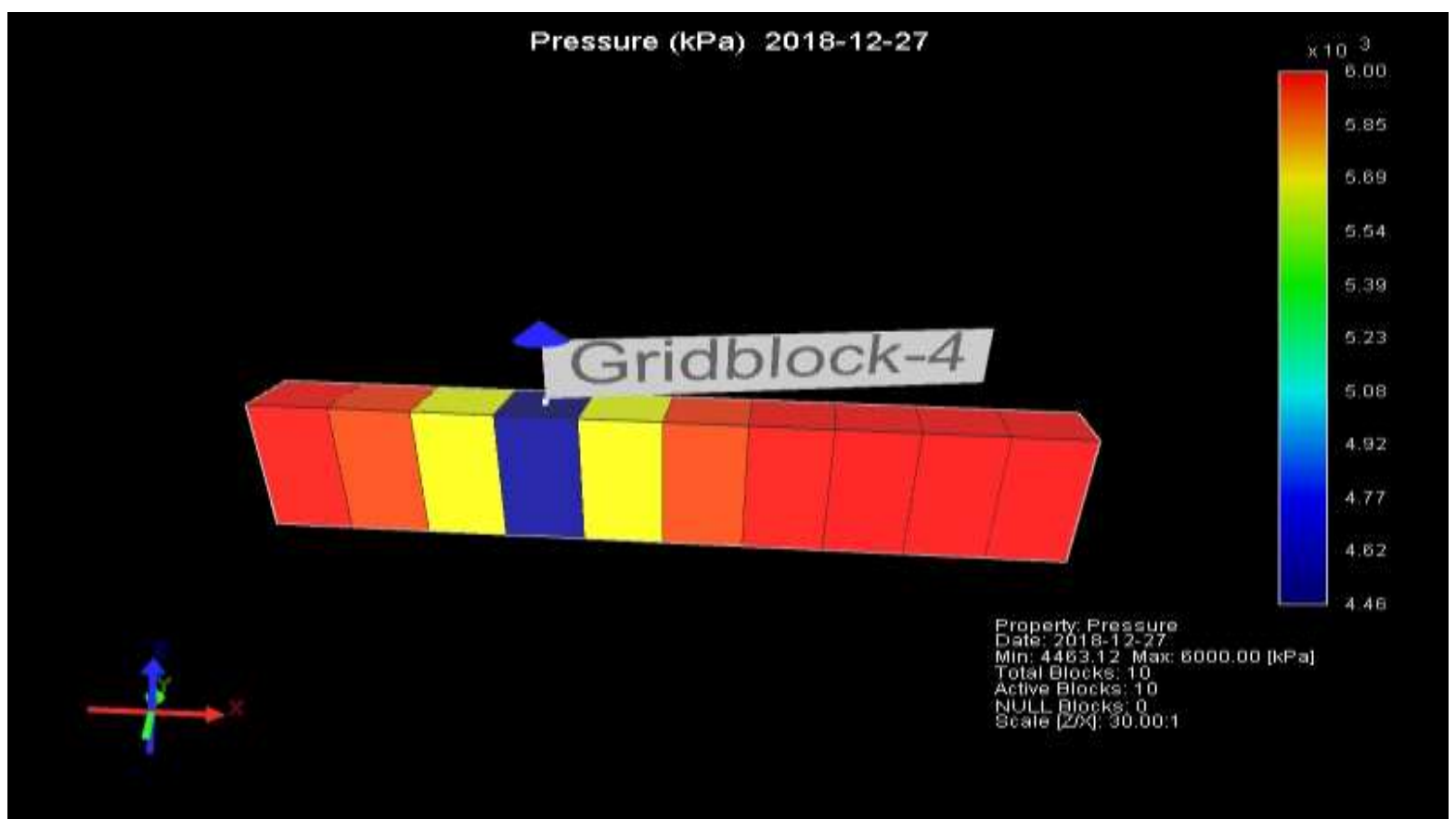

Figure 15. Pictorial view of Reservoir model

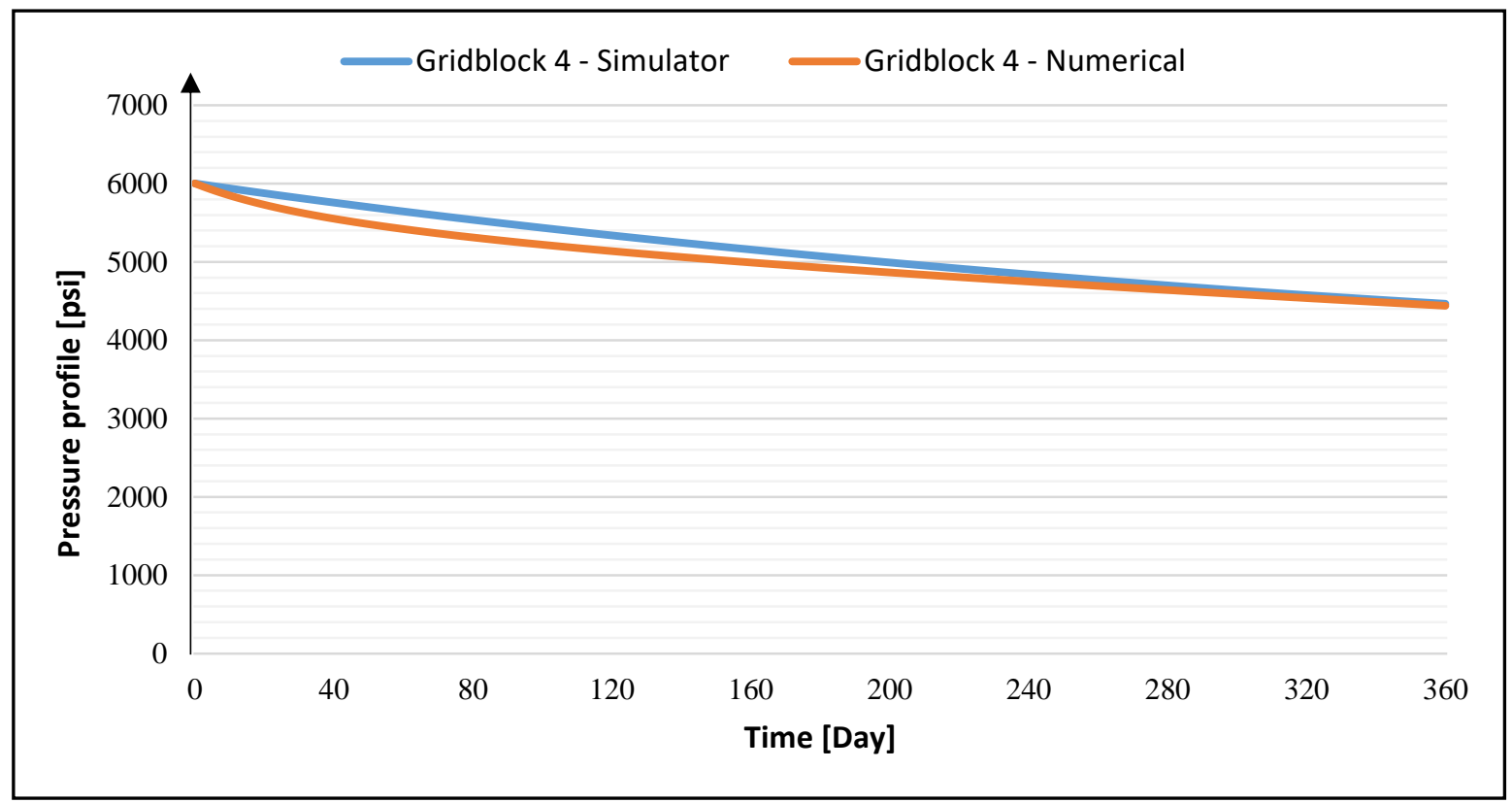

Figure 16. Comparison of simulation results from simulator and numerical codes with timestep of 1 day 


\section{Conclusions}

The pressure distribution in a petroleum reservoir was predicted using both explicit and implicit schemes by providing numerical solutions using MATLAB. The results attained was validated by building a one-dimensional model (black oil ) using CMG simulator to affirm its soundness. From the present study it can be concluded that:

- The explicit scheme exhibited irregular behaviour (negative values of pressures) for timestep of 1 day but yielded a quite satisfactory results for time step of 2 and 3 days, and this can be ascribed to its conditionally stable nature. This makes the errors in the solution of this method goes to zero under certain conditions, while under other conditions these same errors propagate uncontrollably during subsequent timestep calculations. This is a huge shortcoming of the explicit forwarddifference formulation, however is considered efficient since it involves less computations.

- The implicit scheme unconditionally stable nature was confirmed as no poor result of such an explicit case was observed for a timestep of 1 day and even less than 1 day (3,6, and 12 hours respectively). Though this method is more accurate than the explicit method, it is not as computationally efficient as explicit method.

- Moreover, the local truncation error for the implicit method is of order $O\left(k+h^{2}\right)$. The weakness of the implicit method results from the fact that the local truncation error has one of order $O\left(h^{2}\right)$, and another of order $O(k)$. This requires that time intervals be made much smaller than the $\mathrm{x}$-axis intervals. A possible improvement is a method that would give a local truncation error of $O\left(k^{2}+h^{2}\right)$.

- A comparison of the results obtained from the MATLAB codes and the CMG simulator showed a close match thereby affirming the robustness of the implicit scheme in predicting the pressure distribution of the target reservoir. Also, the close correlation between the compared results and the unconditionally stable nature makes the implicit backward difference formulation the most commonly used finite difference formulation in petroleum reservoir simulation.

Future work

- Future study will cover areas such as truncation error due to numerical diffusion, and stability analysis of the explicit method using Courant number which were not accounted for in the present study.

- Also, to take into account both irregular and regular reservoir geometry, other numerical method such as finite volume, finite element, variational or integral method will be employed and compared with the present study.

\section{Nomenclature}

$k_{x} \quad$ Permeability of the reservoir rock in $\mathrm{x}$-direction (Darcy)

$\mu \quad$ Oil viscosity (cp)

$v_{b} \quad$ Gridblock bulk volume (cubic ft)

$\phi \quad$ Porosity of the reservoir rock

$\Phi \quad$ Fluid potential

$c_{t} \quad$ Total compressibility of oil and rock $\left(\mathrm{psia}^{-1}\right)$

B Oil formation volume factor (RB/STB)

$\beta_{c} \quad$ Transmissibility conversion factor

$\alpha_{c} \quad$ Volume conversion factor

$q \quad$ Oil flow rate (STB/Day)

$\Delta x \quad$ Gridblock length (ft)

$\mathrm{A} x \quad$ Area of gridblock cell in $\mathrm{x}$-direction (sq. $\mathrm{ft}$ )

\section{Appendices}

Appendix A: MATLAB Program codes for the Explicit Method

$\%$ Pressure Distribution in Petroleum Reservoir for a Single-phase, Slightly Compressible Fluid Flow

$\% \%$ EXPLICIT METHOD

clc

clear

$\%$ Rock and fluid properties

$\%$ Gridblock dimensions

$\mathrm{dx}=1000$;

$\mathrm{dy}=1000$;

$\mathrm{h}=75$; 
$\mathrm{Kx}=0.015 ; \%$ permeability of the rock in $\mathrm{x}$-direction (Darcy)

$\mathrm{U}=10 ; \quad \%$ oil viscosity (cp)

$\mathrm{Vb}=\mathrm{h} * \mathrm{dx} * \mathrm{dy} ; \%$ gridblock bulk volume (cubic $\mathrm{ft}$ )

$\mathrm{Q}=0.18 ; \%$ porosity

$\mathrm{ct}=3.5 \mathrm{e}-6 ; \%$ total compressibility of oil and $\operatorname{rock}(1 / \mathrm{psia})$

$\mathrm{B}=1 ; \quad \%$ oil formation volume factor (RB/STB)

$\mathrm{Bc}=1.127 ; \%$ transmissibility conversion factor

$\mathrm{V}$ con $=5.615 ; \%$ volume conversion factor

$\mathrm{q}=150 ; \quad \%$ oil production rate at gridblock 4 (STB/day)

$\mathrm{n}=10 ; \quad \%$ number of gridblocks

$\mathrm{Ax}=\mathrm{h} * \mathrm{dy} ; \%$ area of gridblock cell in $\mathrm{x}$-direction (sq.ft)

$\mathrm{Tx}=(\mathrm{Bc} * \mathrm{Ax} * \mathrm{Kx}) /(\mathrm{U} * \mathrm{~B} * \mathrm{dx})$;

$\mathrm{v}=(\mathrm{V} \operatorname{con} * \mathrm{~B} * \mathrm{U}) /(\mathrm{Vb} * \mathrm{Q} * \mathrm{ct})$;

for $\mathrm{dt}=1: 1: 1 \%$ computing for timestep size $\mathrm{dt}=1,2$ and 3 days

$\mathrm{nt}=360 / \mathrm{dt}$;

$\mathrm{P}=\mathrm{zeros}(\mathrm{nt}+1, \mathrm{n})$;

$\mathrm{P}(1,:)=6000$;

for $\mathrm{i}=1: \mathrm{nt}$

$\mathrm{P}(\mathrm{i}+1,1)=\mathrm{P}(\mathrm{i}, 1)+\mathrm{v} *((\mathrm{Tx} * \mathrm{P}(\mathrm{i}, 2))-(2 * \mathrm{Tx} * \mathrm{P}(\mathrm{i}, 1))+(\mathrm{Tx} * \mathrm{P}(\mathrm{i}, 1))) ;$ for $\mathrm{j}=2: 3$

$\mathrm{P}(\mathrm{i}+1, \mathrm{j})=\mathrm{P}(\mathrm{i}, \mathrm{j})+\mathrm{v}^{*}((\mathrm{Tx} * \mathrm{P}(\mathrm{i}, \mathrm{j}+1))-(2 * \mathrm{Tx} * \mathrm{P}(\mathrm{i}, \mathrm{j}))+(\mathrm{Tx} * \mathrm{P}(\mathrm{i}, \mathrm{j}-1))) ;$

end

$\mathrm{P}(\mathrm{i}+1,4)=\mathrm{P}(\mathrm{i}, 4)+(-\mathrm{v} * \mathrm{q})+\mathrm{v} *((\mathrm{Tx} * \mathrm{P}(\mathrm{i}, 5))-(2 * \mathrm{Tx} * \mathrm{P}(\mathrm{i}, 4))+(\mathrm{Tx} * \mathrm{P}(\mathrm{i}, 3)))$;

for $\mathrm{j}=5: 9$

$\mathrm{P}(\mathrm{i}+1, \mathrm{j})=\mathrm{P}(\mathrm{i}, \mathrm{j})+\mathrm{V} *((\mathrm{Tx} * \mathrm{P}(\mathrm{i}, \mathrm{j}+1))-(2 * \mathrm{Tx} * \mathrm{P}(\mathrm{i}, \mathrm{j}))+(\mathrm{Tx} * \mathrm{P}(\mathrm{i}, \mathrm{j}-1))) ;$

end

end

$\mathrm{P}(\mathrm{i}+1,10)=\mathrm{P}(\mathrm{i}, 10)+\mathrm{v}^{*}((\mathrm{Tx} * \mathrm{P}(\mathrm{i}, 10))-(2 * \mathrm{Tx} * \mathrm{P}(\mathrm{i}, 10))+(\mathrm{Tx} * \mathrm{P}(\mathrm{i}, 9)))$;

$\operatorname{disp}(\mathrm{P})$

end

$\% \%$ PLOTTING

$\%$ I. A 3-D PLOT OF PRESSURE DISTRIBUTION

figure (1)

$\mathrm{t}=0: 1: 360$;

Ds $=1: 1: 10$;

$\operatorname{surf(Ds,t,P)}$

$\mathrm{h}=$ colorbar;

title('Pressure Distribution for a year (360 days) with a timestep of 1 day')

xlabel('Gridblocks')

ylabel('Time(Days)')

zlabel('Pressure [Psia]')

shading interp;

colormap jet;

figure (2)

$\%$ A 2-D PLOT OF PRESSURE DISTRIBUTION AGAINST TIME

$\operatorname{plot}(\mathrm{t}, \mathrm{P})$

title('Pressure Distribution for a year (360 days) with a timestep of 1 day')

xlabel('Time [Day]')

ylabel('Pressure [Psia]')

legend('Gridblock1','Gridblock 2','Gridblock 3', 'Gridblock 4','Gridblock 5', 'Gridblock 6','Gridblock 7','Gridblock 8', 'Gridblock 9','Gridblock 10')

grid on

$\% \%$ PROGRAM ENDS 
Appendix B: MATLAB Program codes for the Implicit Method

$\%$ Pressure Distribution in Petroleum Reservoir for a Single-phase, Slightly Compressible Fluid Flow

$\% \%$ IMPLICIT METHOD

clc

clear

for $\mathrm{dt}=1: 1: 1 \%$ computing for timestep size $\mathrm{dt}=1,2$ and 3 days

$\%$ Rock and fluid properties

$\%$ Gridblock dimensions

$\mathrm{dx}=1000$;

$\mathrm{dy}=1000$;

$\mathrm{h}=75$;

$\mathrm{Kx}=0.015$; \% permeability of the rock in $\mathrm{x}$-direction (Darcy)

$\mathrm{U}=10 ; \quad \%$ oil viscosity (cp)

$\mathrm{Vb}=\mathrm{h} * \mathrm{dx} * \mathrm{dy} ; \%$ gridblock bulk volume (cubic $\mathrm{ft}$ )

$\mathrm{Q}=0.18 ; \%$ porosity

$\mathrm{ct}=3.5 \mathrm{e}-6 ; \%$ total compressibility of oil and $\operatorname{rock}(1 / \mathrm{psia})$

$\mathrm{B}=1 ; \quad \%$ oil formation volume factor (RB/STB)

$\mathrm{Bc}=1.127 ; \%$ transmissibility conversion factor

$\mathrm{Vcon}=5.615 ; \%$ volume conversion factor

$\mathrm{q}=150 ; \quad \%$ oil flow rate (STB/day)

$\mathrm{n}=10 ; \quad \%$ number of gridblocks

$\mathrm{Ax}=\mathrm{h} * \mathrm{dy} ; \%$ area of gridblock cell in $\mathrm{x}$-direction (sq.ft)

$\operatorname{Po}=$ zeros $(10,1)$;

$\operatorname{Po}(:, 1)=6000$;

$\mathrm{v}=(\mathrm{Vb} * \mathrm{Q} * \mathrm{ct}) /(\mathrm{V} \operatorname{con} * \mathrm{~B} * \mathrm{dt})$;

$\%$ Coefficients of the resulting tridiagonal matrix

$\mathrm{E}=(\mathrm{Bc} * \mathrm{Ax} * \mathrm{Kx}) /(\mathrm{U} * \mathrm{~B} * \mathrm{dx})$;

$\mathrm{W}=(\mathrm{Bc} * \mathrm{Ax} * \mathrm{Kx}) /(\mathrm{U} * \mathrm{~B} * \mathrm{dx})$

$\mathrm{C}=((-2 * \mathrm{Bc} * \mathrm{Ax} * \mathrm{Kx}) /(\mathrm{U} * \mathrm{~B} * \mathrm{dx}))-\mathrm{v}$;

$\mathrm{E} 1=\mathrm{E} ; \mathrm{E} 2=\mathrm{E} ; \mathrm{E} 3=\mathrm{E} ; \mathrm{E} 4=\mathrm{E} ; \mathrm{E} 5=\mathrm{E} ; \mathrm{E} 6=\mathrm{E} ; \mathrm{E} 7=\mathrm{E} ; \mathrm{E} 8=\mathrm{E} ; \mathrm{E} 9=\mathrm{E} ; \mathrm{E} 10=\mathrm{E} ; \mathrm{E} 11=\mathrm{E} ;$

$\mathrm{W} 2=\mathrm{W} ; \mathrm{W} 3=\mathrm{W} ; \mathrm{W} 4=\mathrm{W} ; \mathrm{W} 5=\mathrm{W} ; \mathrm{W} 6=\mathrm{W} ; \mathrm{W} 7=\mathrm{W} ; \mathrm{W} 8=\mathrm{W} ; \mathrm{W} 9=\mathrm{W} ; \mathrm{W} 10=\mathrm{W} ; \mathrm{W} 11=\mathrm{W} ; \mathrm{W} 12=\mathrm{W}$;

$\mathrm{C} 2=\mathrm{C} ; \mathrm{C} 3=\mathrm{C} ; \mathrm{C} 4=\mathrm{C} ; \mathrm{C} 5=\mathrm{C} ; \mathrm{C} 6=\mathrm{C} ; \mathrm{C} 7=\mathrm{C} ; \mathrm{C} 8=\mathrm{C} ; \mathrm{C} 9=\mathrm{C} ; \mathrm{C} 10=\mathrm{C} ; \mathrm{C} 11=\mathrm{C} ; \mathrm{C} 12=\mathrm{C}$;

$\mathrm{c} 1=\mathrm{W}+\mathrm{C}$;

$\mathrm{c} 10=\mathrm{E}+\mathrm{C}$;

$\mathrm{P}=$ zeros $(1, \mathrm{n})$;

$\mathrm{P}(1,:)=6000$;

$\%$ Obtaining the pressure distribution for a year (360days) with a timestep $\mathrm{dt}=1,2$ and 3 days

for $\mathrm{z}=1:(360 / \mathrm{dt})$

$\%$ Tridiagonal matrix resulting from the linear systems

$$
\begin{aligned}
& \mathrm{A}=\left[\begin{array}{lllllllllll}
\mathrm{c} 1 & \mathrm{E} 1 & 0 & 0 & 0 & 0 & 0 & 0 & 0 & 0 & \text {; }
\end{array}\right.
\end{aligned}
$$

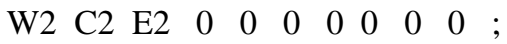

$$
\begin{aligned}
& \begin{array}{lllllllllll}
0 & \mathrm{~W} 3 & \mathrm{C} 3 & \mathrm{E} 3 & 0 & 0 & 0 & 0 & 0 & 0 & \text {; }
\end{array}
\end{aligned}
$$

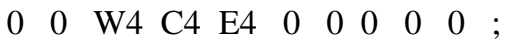

$$
\begin{aligned}
& \begin{array}{lllllllllll}
0 & 0 & 0 & \text { W5 } & \text { C5 } & \text { E5 } & 0 & 0 & 0 & 0 & \text {; }
\end{array} \\
& \begin{array}{lllllllllll}
0 & 0 & 0 & 0 & \text { W6 } & \text { C6 } & \text { E6 } & 0 & 0 & 0 & \text {; }
\end{array} \\
& \begin{array}{lllllllllll}
0 & 0 & 0 & 0 & 0 & \text { W7 } & \text { C7 } & \text { E7 } & 0 & 0 & \text {; }
\end{array} \\
& \begin{array}{lllllllllll}
0 & 0 & 0 & 0 & 0 & 0 & \text { W8 C8 } & \text { E8 } & 0 & \text {; }
\end{array} \\
& \begin{array}{lllllllllll}
0 & 0 & 0 & 0 & 0 & 0 & 0 & \text { W9 } & \text { C9 } & \text { E9 ; }
\end{array}
\end{aligned}
$$

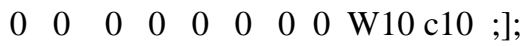

$$
\begin{aligned}
& \% \text { The } \mathrm{b} \text { for the } \mathrm{Ax}=\mathrm{b} \text { linear equations } \\
& \mathrm{b}=\mathrm{zeros}(\mathrm{n}, 1) \text {; } \\
& \text { for } \mathrm{i}=1: \mathrm{n} \\
& \text { if } \mathrm{i} \sim=4 \\
& \mathrm{~b}(\mathrm{i})=-(\mathrm{V} * \mathrm{P}(\mathrm{i})) \text {; }
\end{aligned}
$$




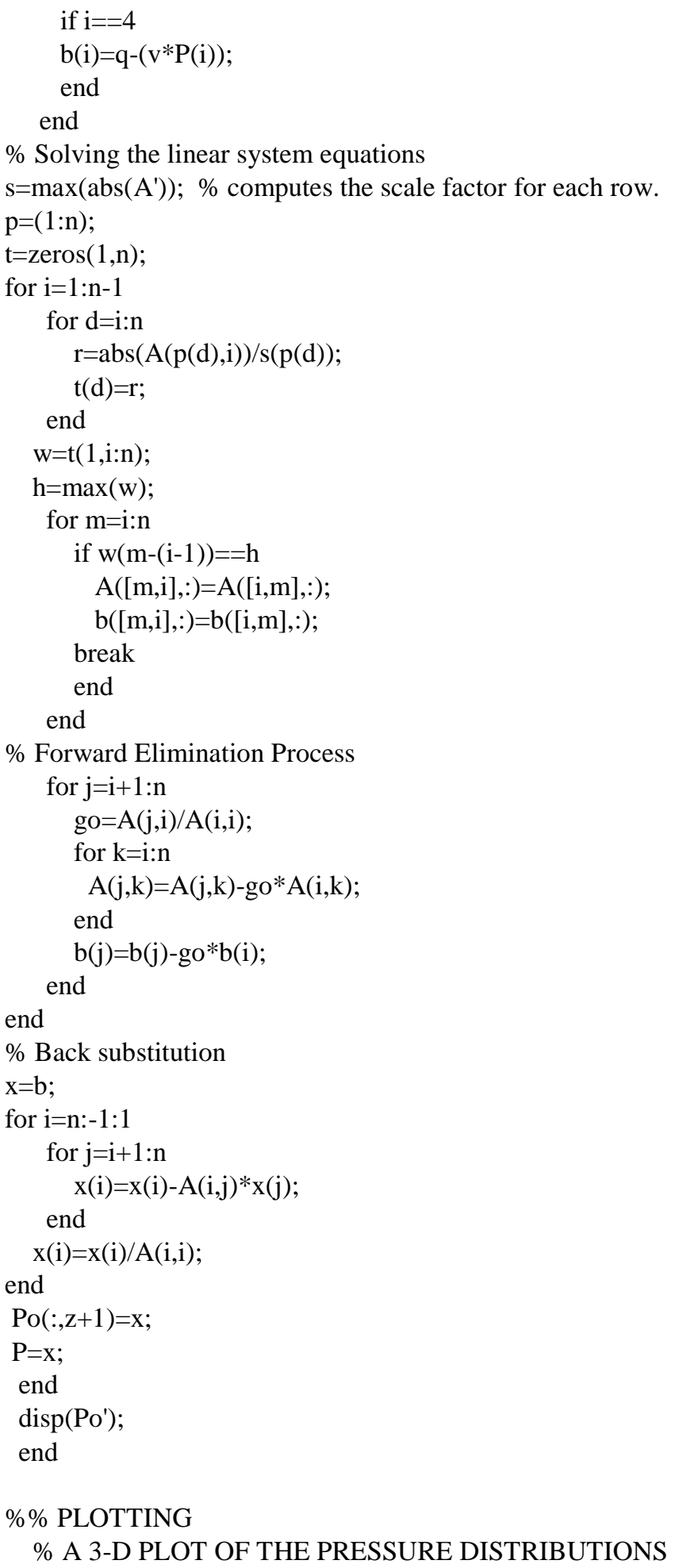

figure (1)

Ds=1:1:10;

$\mathrm{tm}=0: 1: 360$

$\operatorname{surf}\left(\mathrm{Ds}, \mathrm{tm}, \mathrm{Po}^{\prime}\right)$

$\mathrm{h}=$ colorbar;

title('Pressure Distribution for a year (360 days) with a timestep of 1 day')

xlabel('Gridblocks')

ylabel('Time(Days)') 
zlabel('Pressure [Psia]')

shading interp;

colormap jet;

\section{$\%$ A 2-D PLOT OF THE PRESSURE DISTRIBUTIONS AGAINST TIME}

figure (2)

$\mathrm{tm}=0: 1: 360$;

$\operatorname{plot}\left(\mathrm{tm}, \mathrm{Po}^{\prime}\right)$

title('Pressure Distribution for a year (360 days) with a timestep of 1 day')

xlabel('Time [Day]')

ylabel('Pressure [Psia]')

legend('Gridblock1','Gridblock 2','Gridblock 3', 'Gridblock 4','Gridblock 5', 'Gridblock 6','Gridblock 7','Gridblock 8', 'Gridblock 9','Gridblock 10')

grid on

$\% \%$ PROGRAM ENDS

\section{Acknowledgements}

The authors appreciate all the anonymous reviewers for their insightful remarks in shaping the paper and Computer Modeling Group $(\mathrm{CMG})$ for providing the commercial simulator needed to complete this work.

\section{References}

Abdullah, M.A., Panda, A., Gupta, S., Joshi, S., Singh, A., Rao, N. 2019. Multi-scale method for modeling and simulation of two phase flow in reservoir using MRST, Petroleum and Coal, Vol. 61, No. 3, pp. 546 - 558.

Abou-Kassem, J.H., 2007. The engineering approach versus the mathematical approach in developing reservoir simulators. Journal of Nature Science and Sustainable Technology, Vol. 1, No. 1, pp. 35-68.

Abou-Kassem, J.H., Farouq Ali, S.M., Islam, M.R., 2006. Petroleum Reservoir Simulation: A Basic Approach, Gulf Publishing Company, Houston, TX, USA.

Ahmed, T., McKinney, P.D., 2005. Advanced Reservoir Engineering, Gulf Professional Publishing, USA.

Ahmed, T., Nathan Meehan, D., 2011. Advanced Reservoir Management and Engineering, Gulf Professional Pub., USA.

Aphu, E.S., Brantson, E.T., Addo, B.J., Akunda, D., 2018. Development of finite difference explicit and implicit numerical reservoir simulator for modelling single phase flow in porous media, Earth Sciences, Vol. 7, No. 6, pp. 242-259.

Aziz, K., Settari, A., 1979. Petroleum Reservoir Simulation, Applied Science Publishers,

Cheng, Y., 2012. Reservoir Simulation. Petroleum Engineering-Upstream. [15] COMSOL Multiphysics Users Guide.

Chen, Z., 2007. Reservoir Simulation: Mathematical Techniques in Oil Recovery, the CBMS-NSF Regional Conference Series in Applied Mathematics, Vol. 77, SIAM, Philadelphia, PA, USA.

Chen, Z., Huan, G., Ma, Y. 2006. Computational Methods for Multiphase Flows in Porous Media. Computational Science and Engineering Series, Vol. 2, SIAM, Philadelphia, PA, USA.

Ertekin, T., Abou-Kassem, J.H., and King, G.R. 2007, Basic Applied Reservoir Simulation, SPE Textbook Series, Volume 10, Richardson, Texas, USA. 2007.

Firoozabadi, A., 1999. Thermodynamics of Hydrocarbon Reservoirs, McGraw-Hill Publishing, USA.

Hogarth, W.L., Noye, B.J., Stagnitti, J., Parlange, J.Y., Bolt, G. 1990. A comparative study of finite difference methods for solving the one-dimensional transport equation with an initial-boundary value discontinuity. Computers \& Mathematics with Applications, Vol. 20, No. 11, pp. $67-82$.

Hossain, M.E., 2010. The Real Challenges in Reservoir Simulation, $2^{\text {nd }}$ Saudi Meeting on Oil and Natural Gas Exploration and Production Technologies (OGEP 2010), King Fahd University of Petroleum \& Minerals (KFUPM) Campus, Dhahran, Kingdom of Saudi Arabia, December 18-20, 2010.

Islam, M.R., Hossain, M.E., Hossien Mousavizadegan, S., Mustafiz, S., Abou-Kassem, J.H., 2016. Advanced Petroleum Reservoir Simulation: Towards Developing Reservoir Emulators. John Wiley \& Sons, USA.

Khormali, A., Moradi, S.S.T., Petrakov, D., 2014. Study of explicit finite difference method in one dimensional system, International Journal of Computer and Information Engineering, Vol. 8, No. 2, pp. 399-403.

Martynenko, S.I., 2017. The Robust Multigrid Technique: For Black-Box Software, Walter de Gruyter, Berlin, Germany.

Marcondes, F., Maliska, C., Zambaldi, M.C. 2009. A Comparative Study of Implicit and Explicit Methods Using Unstructed Voroni Meshes in Petroleum Reservoir Simulation. Journal of the Brazilian Society of Mechanical Sciences, Vol. 31, No. 4, pp. 353.

Moghaddam, B., Mostgahim, Z.S. 2013. A numerical method based on finite difference for solving fractional delay differential 
equations. Journal of Taibah University for Science, Vol. 7, No. 3, pp. $120-127$.

Mustafiz, S., Islam, M.R., 2008. State-of-the-art: Petroleum Reservoir Simulation. Petroleum Science and Technology, Vol. 26, No. 10-11, pp. 1303-1329.

Shao, Q., Matthai, S.K., Gross, L. 2019. Efficient modelling of solute transport in heterogeneous media with discrete event simulation. Journal of Computaional Physics, Vol 384, No. 1, pp. $134-150$.

Shen, L., Cui, T., Liu, H., Zhu, Z., Zhong, H., Chen, Z., Yang, B., He, R., Liu, H. 2019. Numerical simulation of two-phase flow in naturally fractured reservoirs using dual porosity method on parallel computers: numerical simulation of two-phase flow in naturally fractured reservoirs. 2019 Proceedings of the International Conference on High Performance Computing in AsiaPacific Region, Guangzhou, China.

Sun, X., Sun, M., Takabatake, K., Pain, C.C., Sakai, M. 2019. Numerical Simulation of Free Surface Fluid Flows through Porous Media by Using the Explicit MPS Method. Transport in Porous Media, Vol. 127, No. 1, pp. 7 - 33.

Sood, K., 2016. Solver Schemes for Linear Systems, Oral Comprehensive Exam Position Paper. Dept. of Computer and Information Science, University of Oregon, USA.

Xu, Y., Fernandes, B.R.B., Marcondes, F., Sepehrnoori, K. 2019. Embedded discrete fracture modeling for compositional reservoir simulation using corner-point grids. Journal of Petroleum Science and Engineering, Vol. 177, pp. 41 - 52.

\section{Biographical notes}

Prince Opoku Appau is a Master student at the Research Institute of Enhanced Oil Recovery of China University of Petroleum (Beijing), majoring in Petroleum and Natural Gas Engineering. He holds BSc in Petroleum Engineering from University of Mines and Technology, Tarkwa, Ghana. His research interests include reservoir engineering, Enhanced oil recovery, reservoir modelling and simulation, and drilling and completion.

Ohenewaa Kakra Dankwa is a Lecturer at the Petroleum Engineering Department of the University of Mines and Technology, Tarkwa, Ghana. She holds a BSc in Geomatic Engineering from University of Mines and Technology, with MSc \& PhD in Petroleum Engineering from the African University of Science and Technology (AUST) and University of Port Harcourt respectively. Her research interests include productivity enhancement with matrix acidizing fluids, oilfields scales, environmental management, health and safety.

Eric Thompson Brantson is a Lecturer at the Petroleum Engineering Department of University of Mines and Technology, Tarkwa, Ghana. He holds PhD in Oil and Gas Field Development Engineering from China University of Geosciences (Beijing). His research interests include reservoir engineering, reservoir modeling and simulation, EOR and petroleum geoscience.

Received April 2019

Accepted July 2019

Final acceptance in revised form July 2019 